\title{
DATACIONES RADIOCARBÓNICAS DE CONTEXTOS CALCOLÍTICOS AL AIRE LIBRE EN LA CUENCA MEDIA DEL ARLANZÓN (BURGOS, ESPAÑA)
}

\author{
RADIOCARBON DATING OF CHALCOLITHIC OPEN-AIR SITES FROM \\ ARLANZÓN RIVER MIDDLE BASIN (BURGOS, SPAIN)
}

\author{
EDUARDO CARMONA BALLESTERO*
}

Resumen: El registro arqueológico calcolítico de la Cuenca Media del Arlanzón se ha ampliado considerablemente en los últimos 30 años. Sin embargo, la incorporación de dataciones absolutas es prácticamente nula. Como alternativa se ha utilizado sistemáticamente la comparación tipológica, la cual plantea problemas importantes para tal fin. Por esta razón se programó el proyecto "Dataciones absolutas de contextos calcolíticos de la Cuenca Media del Arlanzón (Burgos)”. Los resultados del mismo son limitados y deberán ser completados con más esfuerzos futuros para aumentar la resolución de la información. Sin embargo, han permitido establecer un marco cronológico consistente. El trabajo detalla los resultados del proyecto así como las valoraciones derivadas del marco cronológico proporcionado por las fechas absolutas obtenidas.

Palabras clave: Dataciones AMS, Campos de hoyos, monumentos funerarios, Calcolítico, Meseta Norte

\section{INTRODUCCIÓN}

El estudio del Calcolítico en la Meseta Norte cuenta con problemas diversos a los que no es ajena el área objeto de este trabajo, la Cuenca Media del Arlanzón (CMA). Entre ellos, destaca la dificultad de establecer

* Área de Arqueología, Universidad de Burgos. Facultad de Humanidades y Educación. c/ Villadiego s/n. 09001 Burgos. Correo-e: educarmonaball@gmail.com

\begin{abstract}
In the last 30 years, the chalcolithic archaeological record from river Arlanzón middle basin has been increased considerably. However, new radiocarbon dates have not been incorporated during this time. Alternatively the typological comparison has been systematically used, which poses major problems for such purpose. For this reason we carried out the project "Absolute dating of Chalcolithic contexts in river Arlanzón Middle Basin (Burgos)". The results are limited and in the future the information should be completed with more efforts in order to increase the resolution of data. On the other hand, data have established a consistent time framework. This work details the results of the project and first valuations about the chronological frame provided by the absolute dates.
\end{abstract}

Keywords: AMS dating, Field of pits, monumental graves, Chalcolithic, Northern Meseta

marcos cronológicos bien definidos. Esta carencia, que se ha ido supliendo en otros lugares, sigue siendo un inconveniente en este sector de la Meseta Norte, a pesar de que en los últimos 30 años se ha renovado considerablemente la información arqueológica disponible. Esta renovación ha supuesto la ampliación de manera exponencial de la base empírica sobre un área poco estudiada: se reconocen 306 yacimientos potencialmente calcolíticos en la CMA, de los cuales se han excavado 17 en la actualidad. La razón de este aumento no es otra 
que la convergencia de diversas circunstancias pero, sobre todo, de la intensa actividad arqueológica ligada a la construcción de infraestructuras en la primera década del siglo XXI.

La potencialidad de la información recuperada y la posición geográfica marginal dentro de la Meseta dotan al área de estudio de determinadas particularidades que ponen de relieve la necesidad de investigar en profundidad el registro arqueológico de la CMA. Sin embargo, el tipo de estrategia arqueológica dominante se ha decantado por una caracterización temporal somera de las evidencias, lo que limita considerablemente la aplicabilidad de los datos en la resolución de las problemáticas generales asociadas al Calcolítico. En consecuencia, para poner en valor la información disponible era necesario llevar a cabo una actuación que incidiera en la ordenación temporal de las entidades arqueológicas documentadas. A tal fin se diseñó el proyecto "Dataciones absolutas de contextos calcolíticos de la Cuenca Media del Arlanzón (Burgos)”. Este trabajo detalla los resultados así como las valoraciones derivadas del mismo.

\section{ANTECEDENTES Y PROBLEMÁTICA}

Como hemos señalado, la periodización y definición temporal del Calcolítico en la Meseta cuenta con importantes problemas. Algunos de ellos son de tipo metodológico, otros se relacionan con el tipo de yacimiento predominante. Trataremos de esbozar brevemente cada uno de ellos.

Un problema generalizado en la Meseta Norte es la pervivencia de métodos de datación relativa, básicamente tipología comparada, que no permiten gran detalle a la hora de afinar en la cronología. Para este fin se suele hacer uso de la cerámica decorada, por lo general escasa, dentro del registro arqueológico calcolítico. Esta situación es especialmente grave para la fase Precampaniforme, dadas las bajísimas frecuencias de cerámicas con elementos ornamentales y de rasgos formales significativos. La utilización con criterios cronológicos de la presencia-ausencia de determinadas piezas ha demostrado tener un margen de error demasiado elevado. $\mathrm{Su}$ uso puede ser válido para la ubicación de las evidencias dentro de fases o periodos generales pero dificulta el establecimiento de vínculos temporales entre contextos.

En este sentido, a la CMA se ha trasladado la periodización y definición temporal del Calcolítico en la Meseta; es decir, se ha dividido en dos etapas diferenciadas: una fase inicial o Precampaniforme, cuyos fósiles-guía más relevantes en este sector son las cerámicas decoradas con pastillas repujadas, triángulos rellenos de puntos y las líneas simples bajo el borde, y una fase final o Campaniforme, identificada por la presencia de piezas campaniformes de estilo internacional pero, sobre todo, por las de estilo Ciempozuelos. Desde un punto de vista temporal, lo máximo que se puede precisar utilizando este método es que los contextos se pueden ubicar dentro del hiato 3300-2400 cal BC para el Precampaniforme y entre el 2600-1900 cal $\mathrm{BC}$ para el Campaniforme, según las comparaciones con los contextos datados en la Meseta Central (Benet et al. 1996; Cantalapiedra e Ismodes 2010; Carretero et al. 2008; Castro et al. 1996: 100-02, 46; Delibes et al. 1996; Delibes et al. 1997: 798; Delibes y Herrán 2007: 195; Díaz del Río 2003: 73; Estremera 2003: 184-85; Fabián 1995: apéndice; Id. 2006: 472; Garrido 2000: 195-98; Garrido et al. 2005: 425-26; Herrán 1986: 118; Jimeno et al. 1988; Liseau et al. 2008: 99; Martín y Delibes 1989; Municio y Piñón 1990; Priego y Quero 1992: 368-69; Santoja et al. 1982; Val 1992: 59). Por lo tanto, esta carencia de información temporal limita el alcance del registro arqueológico a la hora de establecer inferencias que superen los planteamientos arqueográficos.

A pesar de que esta situación se está soslayando en algunas zonas de la Meseta, la datación a través de métodos radiocarbónicos no es una práctica extendida en el sector nororiental, y menos aún en la CMA. Esto se deriva, principalmente, del tipo de gestión arqueológica predominante. En el caso de las excavaciones antiguas, salvo excepciones, no se contemplaba este aspecto como necesario; por el contrario, en las actuales, aunque se considera básico, no se realiza debido al incremento económico que esto supone. Es cierto, no obstante, que se cuenta con algunas fechas obtenidas dentro de programas de investigación consolidados en el ámbito de investigación propuesto (Carretero et al. 2008; Juez 2005; Moral 2002; Vergés et al. 2002). Sin embargo, proceden de contextos muy específicos (yacimientos en cueva ubicados en un espacio particular, la Sierra de Atapuerca) que contrastan con un expresivo vacío de los yacimientos al aire libre, donde las referencias son puntuales: por ejemplo, Los CascajosEl Blanquillo (Martínez 1989), con determinaciones del Neolítico y Bronce Medio, o el Castillo de Burgos (González 1991, 1992; Uríbarri et al. 1987: 167), donde las fechas remiten a momentos del Bronce Final-Hierro I. Es evidente que existe un desequilibrio en la información disponible: una inmensa mayoría de 
contextos ubicados al aire libre sin dataciones frente a una mínima parte, los vinculados a cuevas, con una amplia información radiométrica. Es imprescindible compensar este desequilibrio.

El tipo de estrategia que acabamos de describir es particularmente negativo en relación al tipo de yacimiento predominante en el Calcolítico local: los campos de hoyos. Estas formaciones arqueológicas están constituidas por una acumulación de estructuras negativas (y sus rellenos) sin una correlación física en la mayoría de los casos, lo que limita la capacidad de interconectar eventos temporales a través de la estratigrafía. El problema no es menor, por cuanto supone un importante lastre a la hora de proponer interpretaciones cuando no se dispone más que de fechas relativas que establecen horquillas temporales excesivamente vastas. Esta cuestión se puede solucionar, al menos parcialmente, incorporando programas metodológicos dirigidos a la datación absoluta.

De más complicada solución es otro de los problemas vinculado a los campos de hoyos: la importancia de determinar con exactitud el proceso de formación y transformación de los contextos. No vamos a entrar a analizar en profundidad el tema, del que existe una abundante bibliografía (Anderson-Whymark y Thomas 2012; Bellido 1996; Blanco 2011; Carmona 2012; Cunliffe 1992; Chapman 2000; Jiménez y Márquez 2006; Márquez y Jiménez 2010; Pollard 2001), pero sí es conveniente señalar la relación de este aspecto con la dificultad de saber exactamente lo que se está datando. En la mayoría de las ocasiones es difícil establecer la verdadera sincronía del material que colmata las estructuras, puesto que no se puede establecer con nitidez el origen de los rellenos. Por otro lado, es cierto que en algunos casos sí es posible saber que se está datando un evento en concreto, sobre todo cuando se localizan algunos depósitos estructurados (structured deposition) (Richards y Thomas 1984). Pero en uno y otro caso, el problema esencial es la falta de relación física entre los distintos contextos que imposibilita establecer relaciones temporales relativas a través de la estratigrafía para determinar el orden cronológico de los acontecimientos. De este modo, cada hoyo se convierte en una isla de información difícilmente correlacionable con el resto.

Es preciso señalar también la controversia sobre la consideración de los campos de hoyos como verdaderos lugares de hábitat o domésticos. El análisis de las evidencias detectadas en la CMA (Carmona 2012) determina que estos agregados son las unidades básicas de producción, reproducción y consumo de las comunidades. En ellos se detecta una racionalidad que delimita espacios de residencia, almacenaje y producción contiguos. De esta manera se articulan como distribuciones sociales orgánicas cuyo fin es la reproducción de la comunidad campesina. Estos lugares se configuran como espacios extensos semiabiertos o abiertos en los que se concentran las actividades de las comunidades humanas, pudiendo considerar que en ellos se desempeña la vida doméstica.

Finalmente, un aspecto específico de la CMA es que, como alternativa a los campos de hoyos, las únicas evidencias son las cavidades de la Sierra de Atapuerca y los monumentos megalíticos con fases de uso del Calcolítico Final (Campaniforme). Ambas formaciones arqueológicas manifiestan una orientación muy determinada: su carácter funerario. La información de unos y otros tipos de contextos debe ponerse en relación para tratar de observar sincronías y diacronías en la formación del registro arqueológico calcolítico.

\section{OBJETIVOS}

Atendiendo a la problemática planteada se establecieron una serie de objetivos para el trabajo:

1. Establecer la cronología de los contextos arqueológicos conocidos a través de la obtención de dataciones absolutas.

2. Establecer las relaciones tanto diacrónicas como sincrónicas de las diferentes entidades arqueológicas.

3. Establecer una periodización para las entidades arqueológicas del III milenio cal BC al aire libre en la CMA.

\section{METODOLOGÍA}

Para alcanzar los objetivos propuestos se diseñó una metodología destinada a la obtención de determinaciones radiométricas. El plan inicial contemplaba la realización de un muestreo sobre los 17 yacimientos excavados. De la muestra se descartaron los ya datados de la Sierra de Atapuerca, por lo que el número se reducía a 15 yacimientos distintos.

Como hemos señalado, raramente se había contemplado la datación radiocarbónica por los equipos de excavación, por lo que, en primer lugar, fue necesario realizar una valoración de toda la información arqueológica (informes técnicos, artículos científicos, monografías, memorias de excavación,...) relacionada con 


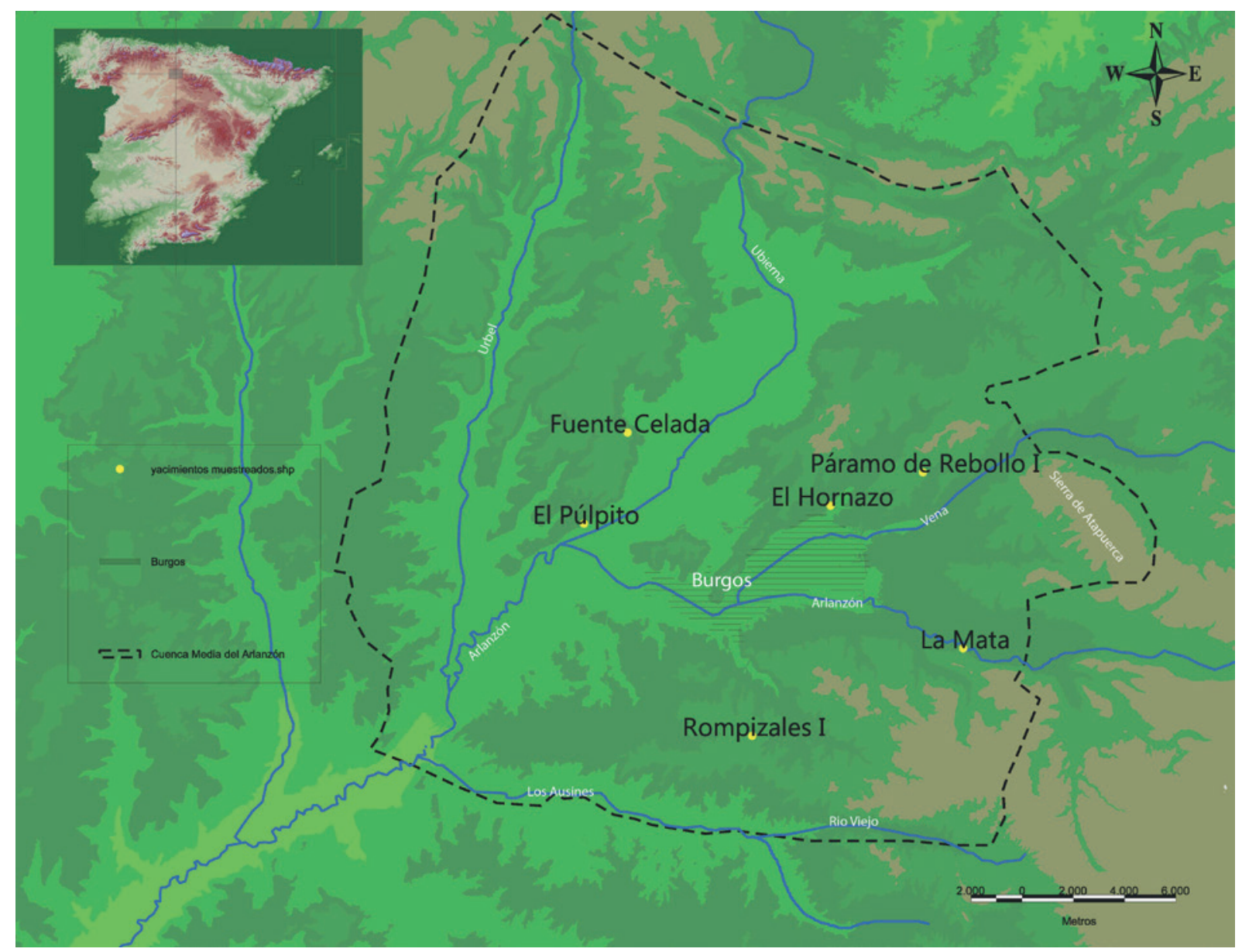

Figura 1. Localización de los yacimientos datados.

los yacimientos calcolíticos en el ámbito de estudio. Se trataba de confirmar la existencia de restos orgánicos conservados en los susceptibles de servir como muestras. En este sentido, se acreditó la existencia de colecciones óseas que se encontraban depositadas en el Museo de Burgos o en su defecto, todavía bajo custodia de los equipos de excavación. Las muestras óseas, frente a otras como los carbones, son altamente adecuadas debido a que constituyen muestras de "vida corta" (Rubinos 2009: 340-41). Por ello, las muestras seleccionadas proceden de restos óseos faunísticos y humanos con unas condiciones conservación adecuadas.

La muestra también debía representar la variedad de situaciones reconocidas en la zona de estudio: espacios geográficos distintos (páramo-fondo de valle), emplazamientos diferenciados (llano, loma o espigón), materiales con distintas atribuciones (precampaniforme y campaniforme) y orientaciones funcionales diferentes (funerario-doméstico). Dada la imposibilidad de datar todos los contextos arqueológicos, en la selección de los contextos se priorizó la resolución de problemáticas particulares de cada yacimiento. Por ejemplo, se consideró fundamental fechar sectores diversos con el fin de observar fases en la formación de los mismos, contextos con materiales de atribución aparentemente distinta, depósitos estructurados o eventos significativos, como enterramientos en fosa dentro de los campos de hoyos, o hallazgos de especial relevancia. El resultado fue la recopilación de 17 muestras procedentes de 6 yacimientos distintos (fig. 1).

Las muestras fueron enviadas al Center for Applied Isotope Studies (CAIS) de la Universidad de Georgia (USA), para su datación a través de espectrometría del acelerador de partículas (AMS). Para la calibración de los resultados se ha utilizado el programa Oxcal 4.1 y la curva de calibración ItnCal 09 (Reimer et al. 2009).

Como último aspecto, es necesario señalar el origen de la información que se ha utilizado. Las muestras 
proceden de actuaciones diversas, realizadas por equipos distintos, con metodologías diferentes, desligadas entre sí. La consecuencia más evidente es el empleo de nomenclaturas variadas y la aparición de material gráfico poco homogéneo. Aunque en ocasiones se han unificado voces y convenciones gráficas, no siempre ha sido posible. En esos casos, hemos considerado preferible favorecer la fidelidad a las fuentes con el fin de que el rastreo y localización de los datos originales sea más fácil.

\subsection{Resultados: dataciones de los contextos al aire libre}

Todas las dataciones absolutas obtenidas para los yacimientos al aire libre en la CMA (tab. 1), a excepción de la identificada como UGA-7565, se ciñen al marco temporal en el que se reconocen las manifestaciones arqueológicas vinculadas al Calcolítico en la Meseta Central (3300-1900 cal BC).

Dejando al margen la datación neolítica, las fechas obtenidas se reparten en distintos rangos. La mayoría de ellas se circunscribe a la primera mitad del III milenio cal B.C., en concreto dentro de una horquilla temporal que oscila entre el 2900 al 2450 cal BC (11 sobre 17 muestras), rango cronológico que coincide con contextos donde la cronología relativa determina una atribución Precampaniforme. En el rango comprendido entre el 2400 al 2100 cal BC, es decir, dentro del periodo donde se reconoce la convivencia de Precampaniforme con el Campaniforme en la Meseta (Fabián 2006: 470-72; Garrido 2000: 195-98), existen dos determinaciones vinculadas, en este caso, a contextos Precampaniformes. El último rango que está definido por las tres determinaciones que se asocian a contextos Campaniformes. Todas se ciñen al tramo 2200-1900 cal BC., considerado como final del ciclo Calcolítico en la Meseta Norte.

Un aspecto peculiar de las dataciones es el que tiene que ver con el desarrollo amesetado de la curva de calibración en el tramo 4200-4100 BP (Reimer et al. 2009). Tal circunstancia conlleva la obtención de intervalos calibrados particularmente amplios, incluso cuando la desviación típica es relativamente pequeña. La meseta afecta a las muestras UGA-6995, UGA-7559, UGA7562, UGA-7563 y UGA-8820, que revelan una distribución de la edad calibrada que se extiende en un intervalo de gran amplitud ubicado entre los extremos 2890 y 2574 cal BC. Esta misma meseta provoca que las fechas calibradas se solapen, lo que redunda en la dificultad para determinar su sincronía o diacronía.
Las dataciones obtenidas merecen un comentario teniendo en cuenta cada yacimiento en particular.

\subsubsection{El Púlpito}

El yacimiento está ubicado cerca de la localidad de Villalonquejar (Burgos) en la parte baja de una cuesta de páramo, situada de la margen derecha del río Ubierna, el cual discurre a $300 \mathrm{~m}$ al Sur (fig. 2). La superficie del yacimiento es alomada con un marcado buzamiento hacia el Sur. Los datos proceden de la excavación preventiva efectuada en 2009 (Delgado y Villanueva 2010). Las evidencias detectadas se repartían por un área de 0,83 ha, aunque solo se excavaron 0,23 ha, lo que supone el $27,71 \%$ del yacimiento.

El conjunto de evidencias arqueológicas no se distribuía de manera homogénea. Se dividían en dos sectores separados físicamente (fig. 3), en los que se documentaron 20 estructuras distintas. Se documentaron un total de 1.235 restos que se distribuyen de manera desigual entre los hoyos, como lo es el reparto de los materiales en virtud del tipo: 1.092 restos de cerámica; 71 restos faunísticos; 15 elementos líticos tallados y 1 fragmento de un útil pulimentado.

Algunos hoyos (C. 30, 50, 80, 140 y 150) contenían materiales arqueológicos de atribución Precampaniforme: cerámicas decoradas con pastillas repujadas, líneas incisas simples bajo el borde y molduras bajo el borde (Delgado y Villanueva 2010). El resto no aportó material significativo en relación a la atribución. La elección de las muestras se vio supeditada a la presencia de restos faunísticos en los contextos, pues no aparecían en todos. Se pudieron tomar 3: Contexto $10 \mathrm{y}$ Contextos 140 y 150 (fig. 3).

En cuanto a los resultados, un aspecto reseñable es que no se reconoce una relación directa entre la existencia de dos zonas diferenciadas y las cronologías. Al menos las dataciones ofrecen dudas razonables para diferenciar fases en el proceso de formación del yacimiento que aludan a la delimitación de sectores consecutivos en el tiempo. Los rangos temporales que separan las tres determinaciones son altos, por lo que no existen elementos de juicio para discernir entre una ocupación continuada del lugar o recurrente, al menos en cuanto a la interrelación interna de los contextos que conforman el yacimiento.

Por otro lado, los resultados concuerdan con la atribución proporcionada por la cerámica. En este sentido, quizá llama la atención la fecha más moderna de las tres (UGA-6836) y su relación con un conjunto de 
Tabla 1. Dataciones radiocarbónicas obtenidas en los yacimientos al aire libre de la Cuenca Media del Arlanzón

\begin{tabular}{|c|c|c|c|c|c|c|c|}
\hline Yacimiento & ID & Fecha B.P. & Calibración $2 \sigma$ & $\delta 13 \mathrm{C}$ & Material & Contexto & Atribución \\
\hline E1 Púlpito & UGA-6835 & 4270,25 & $2916(95.4 \%) 2877$ & $-21.5 \%$ & Hueso fauna & C10; UE11 & Precampaniforme \\
\hline El Púlpito & UGA-6837 & 4050,25 & $\begin{array}{r}2834(3.6 \%) 2819 \\
2660(1.5 \%) 2650 \\
2634(90.3 \%) 2487\end{array}$ & $-20.5 \%$ & Hueso fauna & C150; UE153 & Precampaniforme \\
\hline El Púlpito & UGA-6836 & 3880,25 & $2465(95.4 \%) 2290$ & $-20.1 \%$ & Hueso fauna & C140; UE141 & Precampaniforme \\
\hline El Hornazo & UGA-7566 & 4290,25 & $2927(95.4 \%) 2878$ & $-20.4 \%$ & Hueso fauna & F94, UE 958 & Precampaniforme \\
\hline El Hornazo & UGA- 8820 & 4200,25 & $\begin{array}{r}2893(27.5 \%) 2850 \\
2814(52.9 \%) 2741 \\
2729(14.4 \%) 2694 \\
2685(0.7 \%) 2680\end{array}$ & $-21.8 \%$ & $\begin{array}{l}\text { Semilla } \\
\text { (Tritucum } \\
\text { aestivium/ } \\
\text { durum) }\end{array}$ & F30; UE 303 & Precampaniforme \\
\hline El Hornazo & UGA-6838 & 4010,25 & $2576(95.4 \%) 2473$ & $-19.4 \%$ & Hueso humano & F103; UE1031 & Precampaniforme \\
\hline El Hornazo & UGA-6995 & 4100,25 & $\begin{array}{r}2860(22.1 \%) 2809 \\
2752(8.0 \%) 2721 \\
2702(65.3 \%) 2574\end{array}$ & $-19.4 \%$ & Hueso humano & F140; UE1401 & Precampaniforme \\
\hline Fuente Celada & UGA-7565 & 6120,30 & $\begin{array}{r}5208(23.4 \%) 5144 \\
5139(9.4 \%) 5091 \\
5083(62.6 \%) 4961\end{array}$ & $-19.5 \%$ & Hueso humano & H62, UE 622 & Neolítico \\
\hline Fuente Celada & UGA-7563 & 4200,25 & $\begin{array}{r}2893(27.5 \%) 2850 \\
2814(52.9 \%) 2741 \\
2729(14.4 \%) 2694 \\
2687(0.7 \%) 2680\end{array}$ & $-21.0 \%$ & Hueso fauna & H42; UE 424 & Precampaniforme \\
\hline Fuente Celada & UGA-7561 & 4170,25 & $\begin{array}{r}2880(19.8 \%) 2835 \\
2817(75.1 \%) 2667 \\
2643(0.5 \%) 2640\end{array}$ & $-20.7 \%$ & Hueso fauna & H15; UE 152 & Precampaniforme \\
\hline Fuente Celada & UGA-7559 & 4100,25 & $\begin{array}{r}2860(22.1 \%) 2809 \\
2752(8.0 \%) 2721 \\
2702(65.3 \%) 2574\end{array}$ & $-19.2 \%$ & Hueso humano & $\begin{array}{l}\text { H5; UE } 53, \\
\text { indiv } 2\end{array}$ & Precampaniforme \\
\hline Fuente Celada & UGA-7562 & 4100,25 & $\begin{array}{r}2860(22.1 \%) 2809 \\
2752(8.0 \%) 2721 \\
2702(65.3 \%) 2574\end{array}$ & $-19.2 \%$ & Hueso humano & H19; UE 193 & Precampaniforme \\
\hline Fuente Celada & UGA-7560 & 4030,25 & $2620(95.4 \%) 2474$ & $-19.0 \%$ & Hueso humano & $\begin{array}{l}\text { H5; UE } 53 \text {, in- } \\
\text { div. } 3\end{array}$ & Precampaniforme \\
\hline Fuente Celada & UGA-7564 & 3790,25 & $2292(95.4 \%) 2140$ & $-20.6 \%$ & Hueso fauna & H60; UE 601 & Precampaniforme \\
\hline La Mata & UGA-7557 & 3670,25 & 2137 (95.4\%) 1965 & $-20.3 \%$ & Hueso fauna & S1, UE3 & Campaniforme \\
\hline Rompizales I & UGA-7558 & 3690,25 & $\begin{array}{r}2192(2.2 \%) 2180 \\
2143(90.1 \%) 2018 \\
1195(3.1 \%) 1981\end{array}$ & $-20.2 \%$ & Hueso fauna & E42,UE1 & Campaniforme \\
\hline $\begin{array}{l}\text { Túmulo IL.C1 de } \\
\text { Cótar/Páramo de } \\
\text { Rebollo I }\end{array}$ & UGA-8821 & 3670,25 & $2137(95.4 \%) 1965$ & $-20.7 \%$ & colágeno & Fosa, N. II & Campaniforme \\
\hline
\end{tabular}




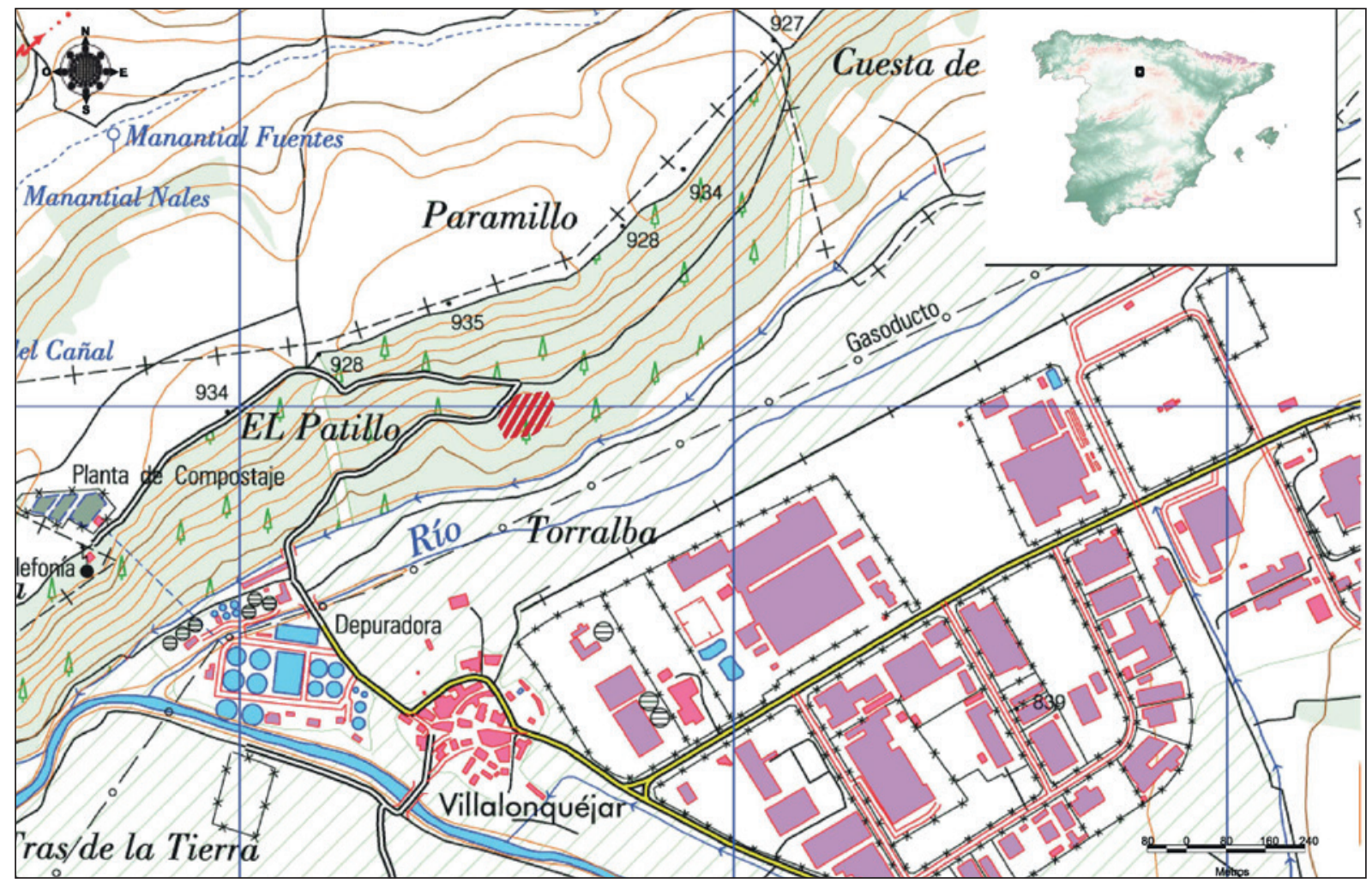

Figura 2. Ubicación de El Púlpito.

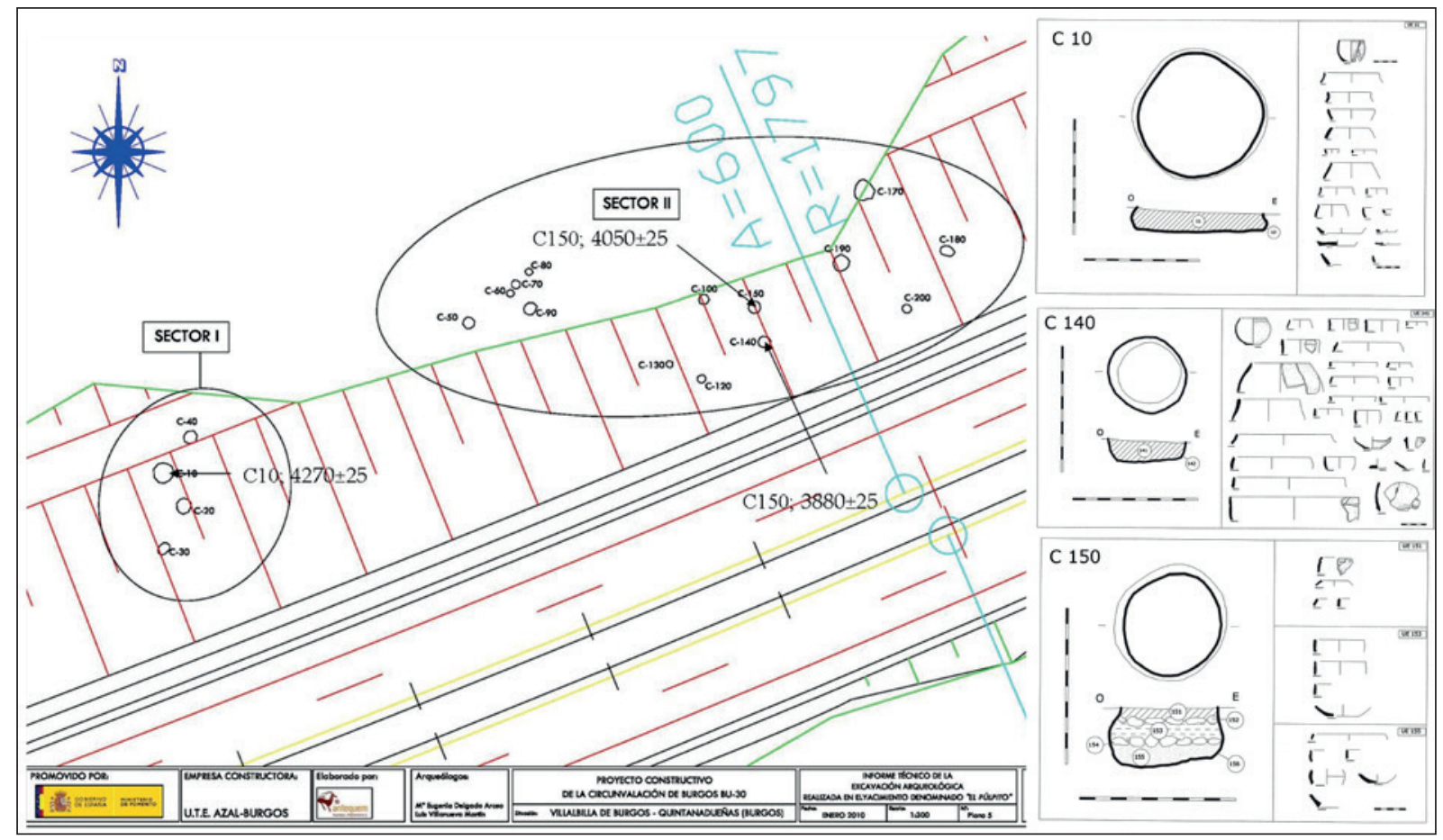

Figura 3. Planta general de El Púlpito con la localización de los contextos datados junto a la planta y sección de cada uno de ellos y los materiales arqueológicos documentados. 


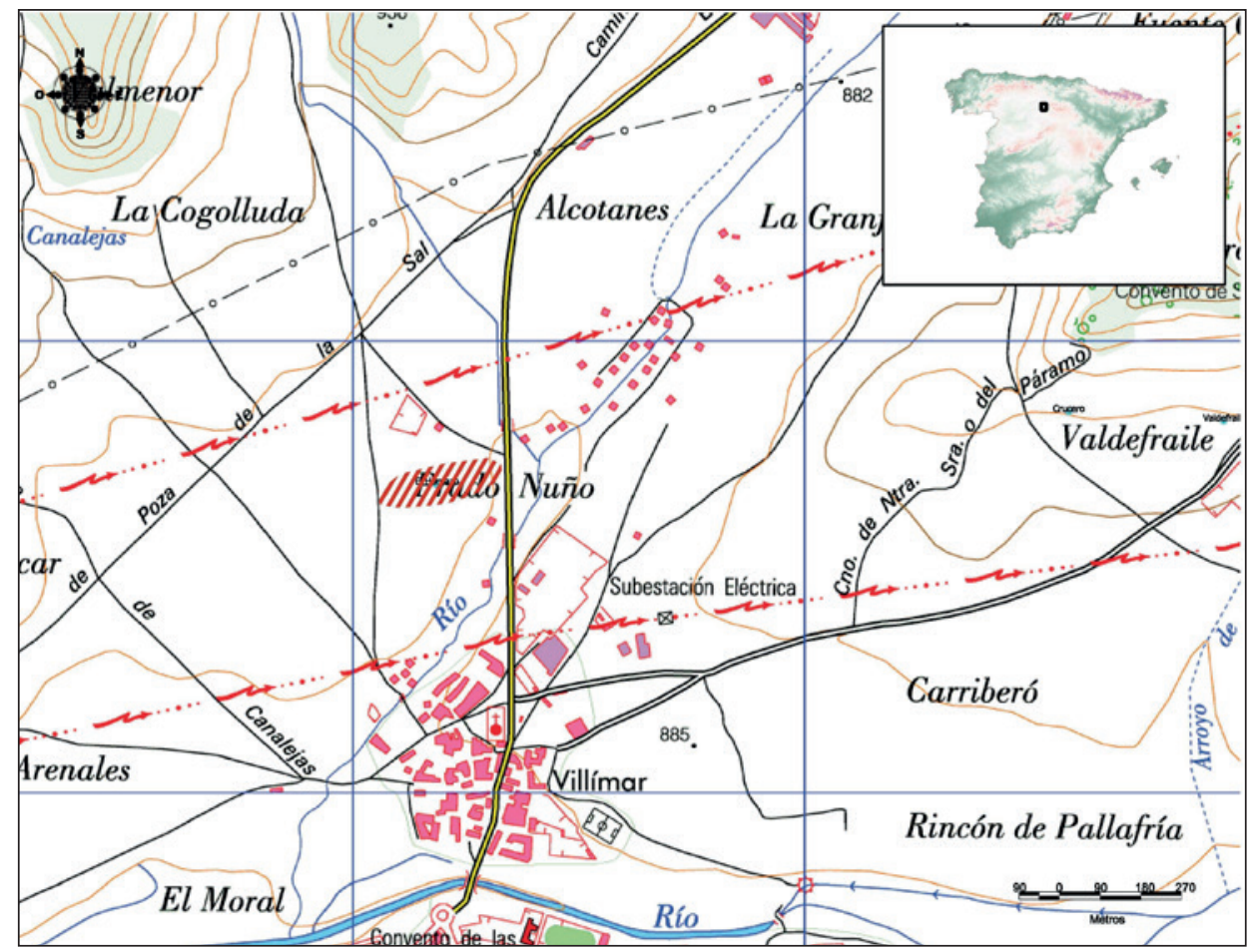

Figura 4. Ubicación de El Hornazo. cerámicas con ciertas peculiaridades que refuerzan la modernidad de la datación, tales como la presencia de un curioso vaso de carena alta y otro decorado con un cordón liso. No obstante, también se reconocen atributos Precampaniformes, como los recipientes con moldura bajo el borde. La datación muestra un aspecto interesante: el reconocimiento de ciertos rasgos tipológicos normalmente asociados al Bronce Antiguo en fechas todavía calcolíticas.

\subsubsection{El Hornazo}

El Hornazo se encuentra situado en las inmediaciones de la localidad de Villímar, dentro del municipio de Burgos. Se ubica en un espacio llano, en la zona de contacto entre las terrazas del río Vena y las cuestas del páramo, emplazado en la margen derecha del río Morquillas, del que dista apenas $200 \mathrm{~m}$ (fig. 4). El yacimiento fue excavado en 2004 a través de una actuación preventiva. La intervención se llevó a cabo sobre un espacio de casi 1 ha. Las dimensiones del yacimiento no se conocen con exactitud pero exceden el área intervenida tanto al norte como al sur. La extensión estimada, a tenor de la información disponible (Pascual Blanco, com. pers.), es de unas 2 ha. El estudio de las evidencias corrió a cargo del firmante del artículo (Carmona 2012: 184-235).

La excavación localizó hoyos y otras evidencias arqueológicas poco habituales en el resto de yacimientos estudiados. En concreto se documentó un conglomerado de 179 estructuras (denominadas por el equipo de excavación Fondos) entre las que se reconocen hoyos siliformes, hoyos de poste, fosas de decantación y fosas complejas, además de una extensa unidad estratigráfica (UE 302) cortada por numerosos hoyos de poste.

El yacimiento se articula en tres espacios distintos (Carmona 2012: 201-202): zona de hábitat, zona de almacenaje y zona de transformación de recursos. En la zona de almacenaje se documentaron dos enterramientos realizados en hoyo (Fondo 103 y 140), de los que se tomaron sendas muestras para datar (fig. 5). Además, se muestreó una de las fosas complejas (Fondo 94) y un hoyo siliforme que conservó su contenido de grano (Fondo 30) (fig. 5). Los materiales arqueológicos se distribuyen de manera desigual por las diferentes estructuras, siendo muy diferente igualmente la representación por tipos: 27.839 restos de cerámica, 991 restos de industria lítica tallada, 1.911 restos de fauna, 8 herramientas sobre hueso, 32 fragmentos de molinos barquiformes, 7 utensilios pulimentados y 331 restos de otra naturaleza 


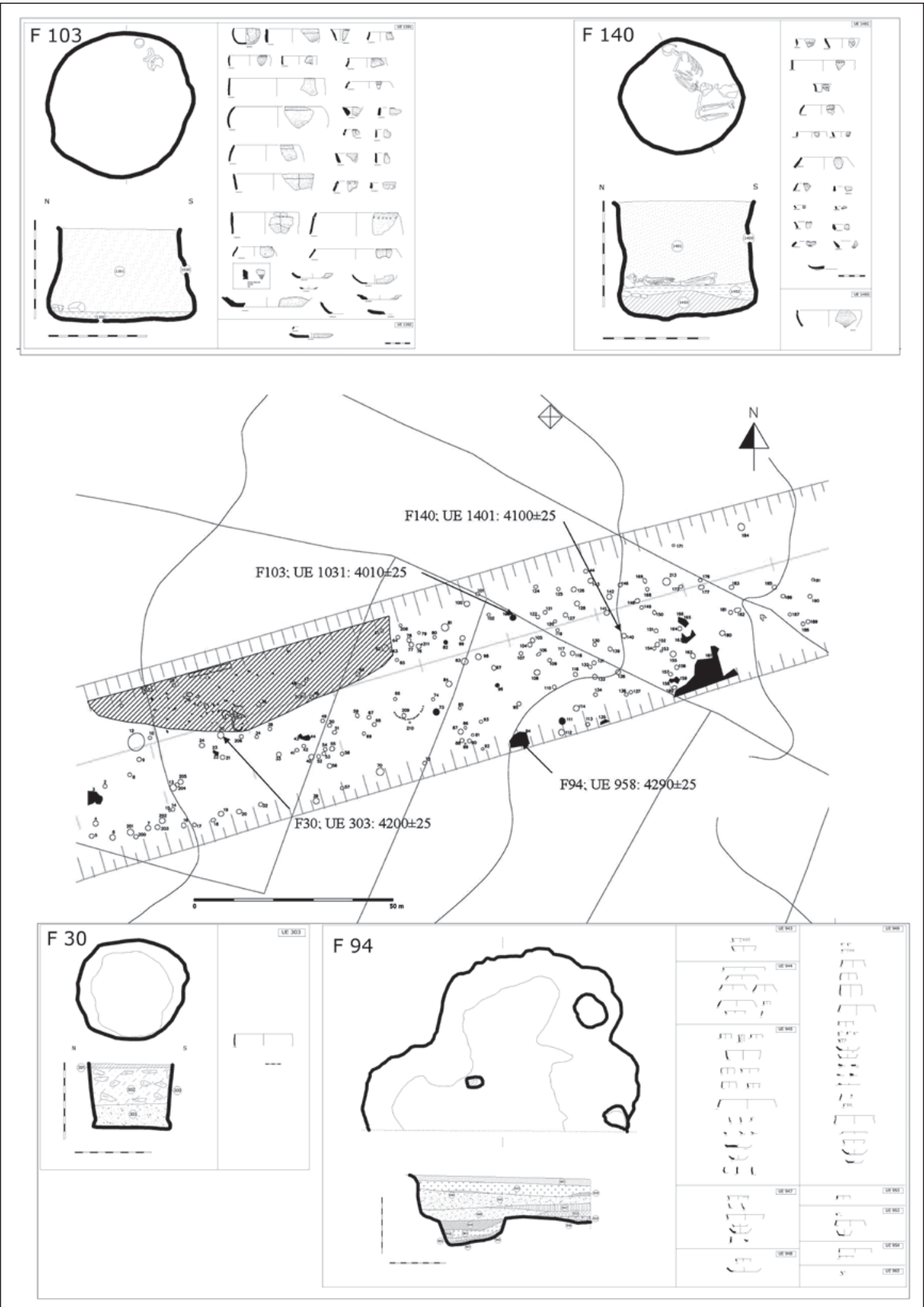

Figura 5. Planta general de El Hornazo. Localización de los contextos datados junto a la planta y sección de cada uno de ellos y los materiales arqueológicos que incluyen. 


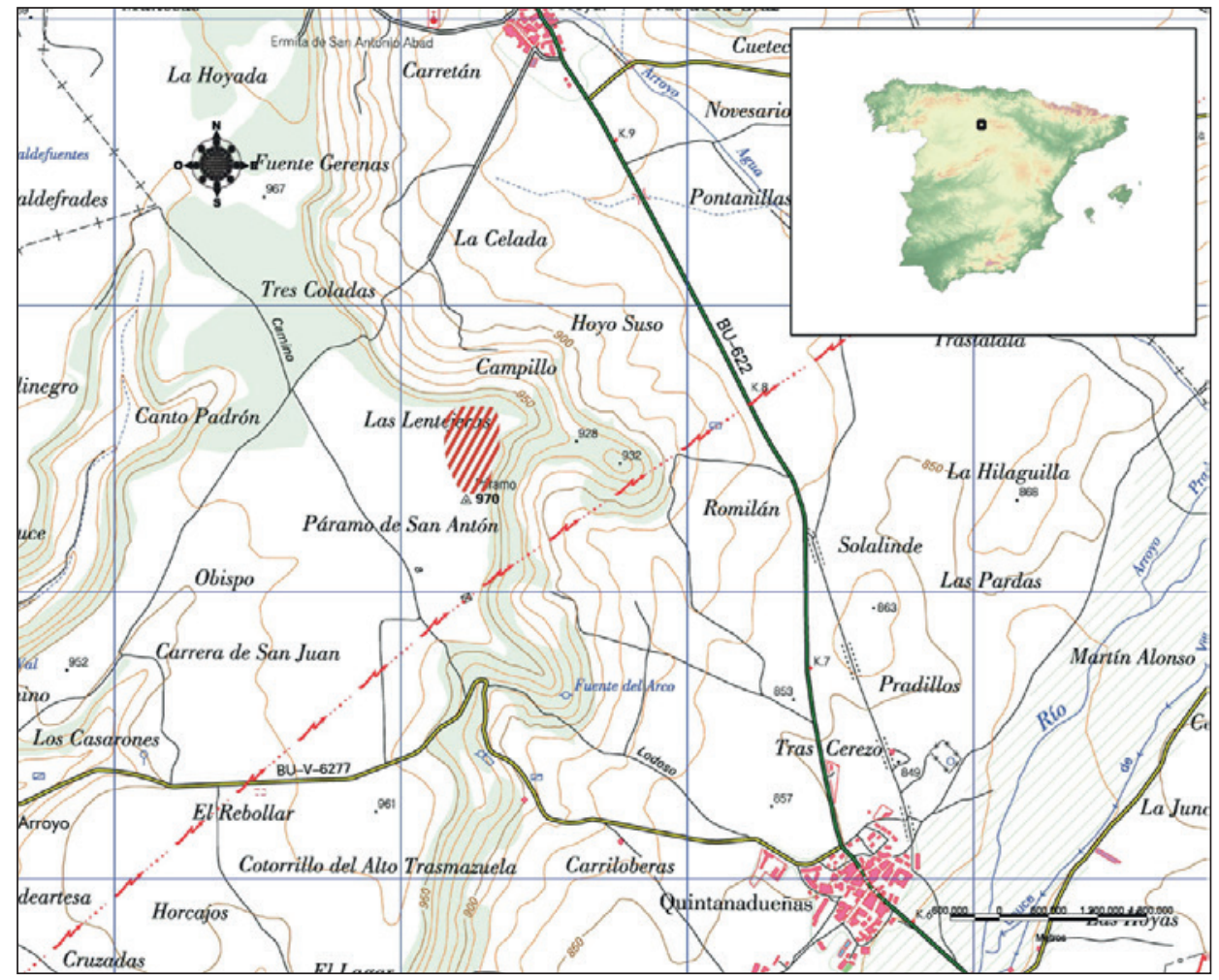

Figura 6. Ubicación de Fuente Celada (malacofauna, manteado de barro, macrotecnología lítica). Las estimaciones realizadas a través del análisis de los parámetros significativos del material arqueológico recuperado indicaban que todo el conjunto se podía integrar dentro de una atribución genérica Precampaniforme (Carmona 2012: 185).

Las dataciones avalan esta observación. Todas las determinaciones se ubican en el rango 2927-2573 cal BC. Este aspecto, junto a la enorme similitud técnica y estilística de las piezas cerámicas (pastillas repujadas, molduras bajo borde, líneas simples bajo el borde y, de manera esporádica, puntos impresos y líneas pintadas), permite considerar que todo el agregado de estructuras negativas se conformó durante una única fase de ocupación dilatada durante el rango temporal señalado.

A pesar de la coherencia de todas ellas, llama la atención la distribución de las fechas: las procedentes de los hoyos siliformes y fosas con evidencias exclusivamente productivas (Carmona 2012: 190-202), son más antiguas que las provenientes de las inhumaciones. Estas últimas se sitúan en un momento avanzado de la ocupación del yacimiento. Las inhumaciones apenas difieren en unas decenas de años entre sí.

\subsubsection{Fuente Celada}

El yacimiento se sitúa en la localidad de Quintanadueñas, concretamente en un espigón de páramo ocupando un área de 3,4 ha (fig. 6). Fue excavado parcialmente $\left(1.310 \mathrm{~m}^{2}\right.$, el 3,8\% de la superficie estimada) en 2008 y 2009 debido a la realización de una actuación preventiva para la construcción de un parque eólico. Los trabajos arqueológicos detectaron un conjunto de 127 contextos de los que únicamente se excavaron 90. Dentro de los mismos se distinguieron hoyos siliformes, agujeros de poste e inhumaciones en hoyo. Los datos recuperados en estas estructuras informaron de la existencia de dos fases distintas de formación del yacimiento (Alameda et al. 2011): una Neolítica, ceñida al sector norte de la excavación, y otra Calcolítica, que se extendía por todo el área excavada.

De Fuente Celada se tomaron 8 muestras procedentes (fig. 7) tanto de las inhumaciones en hoyo (hoyo 5 indiv. 1 , hoyo 5 indiv. 3 , hoyo 19 y hoyo 62) como de hoyos siliformes (hoyo 15, hoyo 42 y hoyo 60). La mayoría de las dataciones se circunscriben a la primera mitad del III milenio cal B.C., en concreto dentro de una horquilla temporal que oscila entre el 2900 al 2475 cal BC. Estas fechas coinciden con contextos donde las piezas 


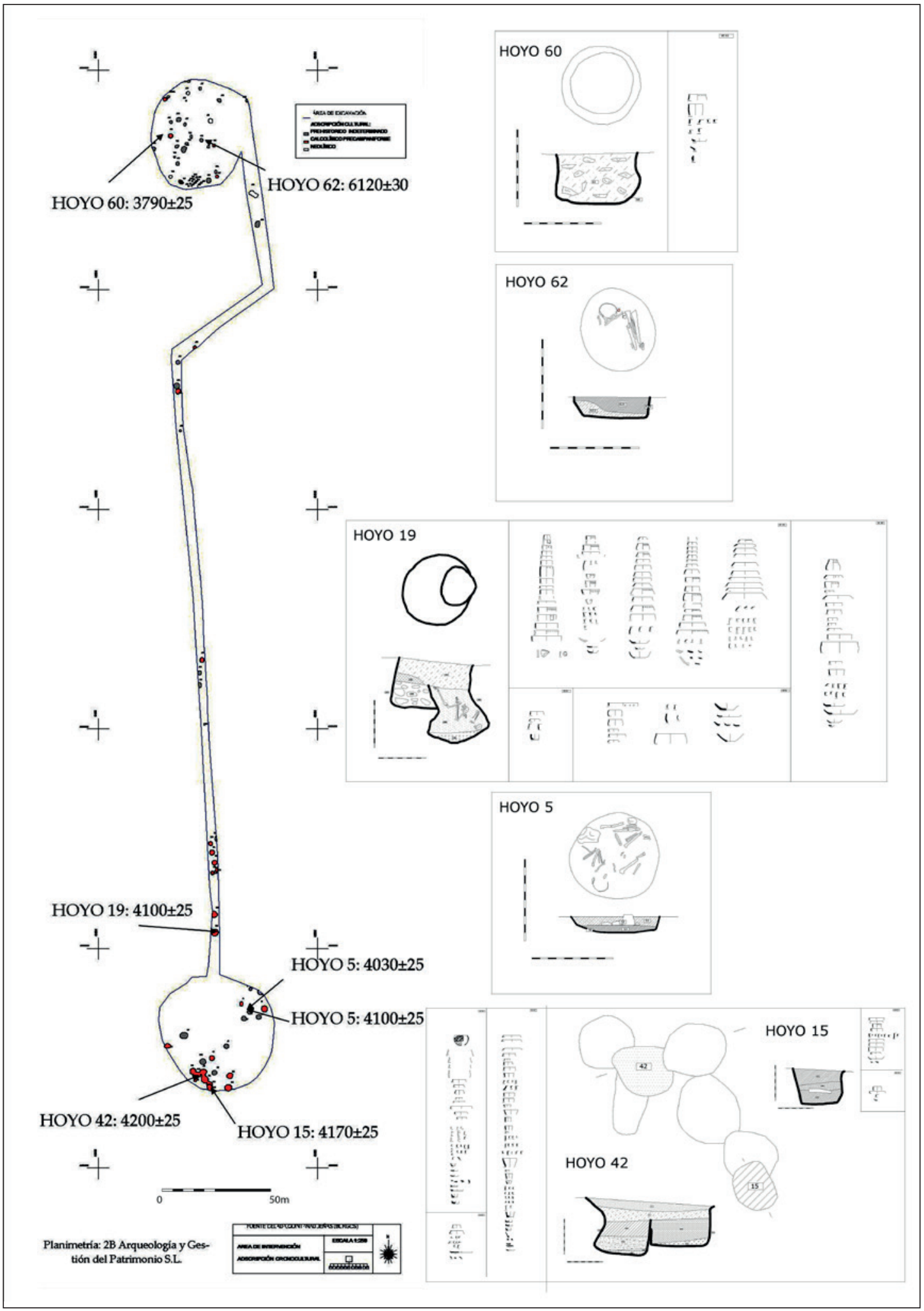

Figura 7. Planta general de Fuente Celada con la localización de los contextos datados, plantas y secciones de todos ellos, y los materiales arqueológicos documentados. 
determinan una atribución precampaniforme. Otro caso es la obtenida en el hoyo 60, que se adentra considerablemente en el rango comprendido entre el 2400 al 2100; es decir, dentro del periodo de vigencia del Calcolítico con Campaniforme. El conjunto cerámico procedente del contexto donde se recuperó la muestra no es muy expresivo (fig. 7), aunque se reconocen perforaciones, acanaladuras y algún mamelón. En este sentido, los tipos y formas concuerdan con las piezas lisas que acompañan a las piezas campaniformes en determinados contextos domésticos (Carmona 2010: 103; Garrido 2000: 40-41). Esta fecha también se relaciona con la única pieza de campaniforme, un pequeño fragmento de estilo Ciempozuelos, que se recuperó en un sondeo previo en el sector norte del yacimiento.

Dejando al margen la primera fase neolítica, los datos indican que hay un lapso de algo más de una centuria entre el grueso de las dataciones y la más moderna de ellas. A ello se suma la desconexión física y las diferencias tipológicas de los materiales entre una y otra fase. Desconocemos, con los datos actuales, el alcance que puede tener esta información en cuanto a su relación con los procesos de formación, uso y abandono del espacio de hábitat.

Por otro lado, llama poderosamente la atención la coetaneidad de los enterramientos de Fuente Celada, que, a su vez, son sincrónicos respecto a los de El Hornazo. Cabe recordar que la presencia de inhumaciones dentro de espacios considerados domésticos durante el Calcolítico todavía continua siendo un tema controvertido; más si cabe cuando se produce una clara coincidencia temporal de este tipo de manifestaciones y teniendo en cuenta que no se corresponden con los hábitos normalizados, sino que se pueden considerar prácticamente una excepción (Fabián y Blanco 2012: 113). Desde nuestro punto de vista tal coincidencia no es casual y se debe relacionar con el marco de relaciones sociales de las comunidades calcolíticas, dentro de un proceso dialéctico de reivindicación de los espacios de producción y reproducción social, tal y como ya propuso Díaz del Río (2001: 291-293).

\subsubsection{La Mata}

Se trata de un yacimiento que se localiza en Castrillo del Val. Se ubica en la margen izquierda del río Arlanzón en un tramo de terrazas fluviales, de cuyo cauce dista unos $350 \mathrm{~m}$. Las actuales características del registro arqueológico de La Mata son el resultado de un cúmulo de prospecciones que se han ido sucediendo a lo largo del tiempo y que han conformado un corpus de datos amplio, pero carente de contexto. El área de dispersión es amplísima (28,34 ha), pero las evidencias superficiales sugieren que en el extremo noreste se puede localizar un espacio de hábitat y almacenamiento, que se reduce a 2,1 ha. En este punto se practicaron dos sondeos de 10,25x1,60 m cada uno (Alonso 2009) (fig. 8). En uno de ellos se detectó un hoyo con material de atribución campaniforme. La datación obtenida procede de este hoyo. Es moderna pero encaja dentro del lapso temporal del Campaniforme en la Meseta Norte: 2500-1900 cal BC. (Castro et al. 1996: 146-47; Garrido 2000: 195-98; Garrido et al. 2005: 425).

\subsubsection{Rompizales I}

El yacimiento se localiza dentro del término municipal de Burgos (fig. 9), en la cabecera del arroyo de Río Pizales, que nace en uno de los cerros que se sitúan al sur de la capital burgalesa. Estos relieves constituyen superficies alomadas donde el límite entre la plataforma de páramo y la zona de cuesta no es nítido.

Este yacimiento se excavó en 2002 mediante una actuación preventiva (Alonso 2003) dividida en dos fases: sondeos previos y excavación en extensión. Los sondeos detectaron una secuencia estratigráfica que acumulaba depósitos y estructuras negativas de varias etapas de la Prehistoria Reciente: Neolítico, Calcolítico Final y Bronce Medio (Carmona 2012: 327-331). La eliminación mecánica de la cobertura vegetal para 1levar a cabo la excavación en área (1,7 ha) no dejó rastro de la secuencia estratigráfica.

La actuación documentó 42 estructuras (zanja perimetral, hoyos siliformes, agujeros de poste, hogares, hornos y manchones) de las cuales 17 (E. 00, 13, $16,22,23,25,26,27,29,30,35,37,39,42,44,49$ y 53) incorporaban cerámica campaniforme (Alonso 2003). Solo se pudo datar una esquirla de material óseo proveniente de una pequeña fosa -E. 42(fig. 10) que se depositó en el Museo de Burgos al ser catalogada erróneamente como un instrumento. Esta estructura incorporaba abundante material campaniforme. La datación se asemeja mucho a la de La Mata, hasta el punto de poder considerarlas contemporáneas. Lamentablemente con una sola fecha no es posible valorar el rango temporal que cubren todas las evidencias arqueológicas detectadas. Únicamente se puede acreditar la sincronía de los hábitats de La Mata y Rompizales I. 


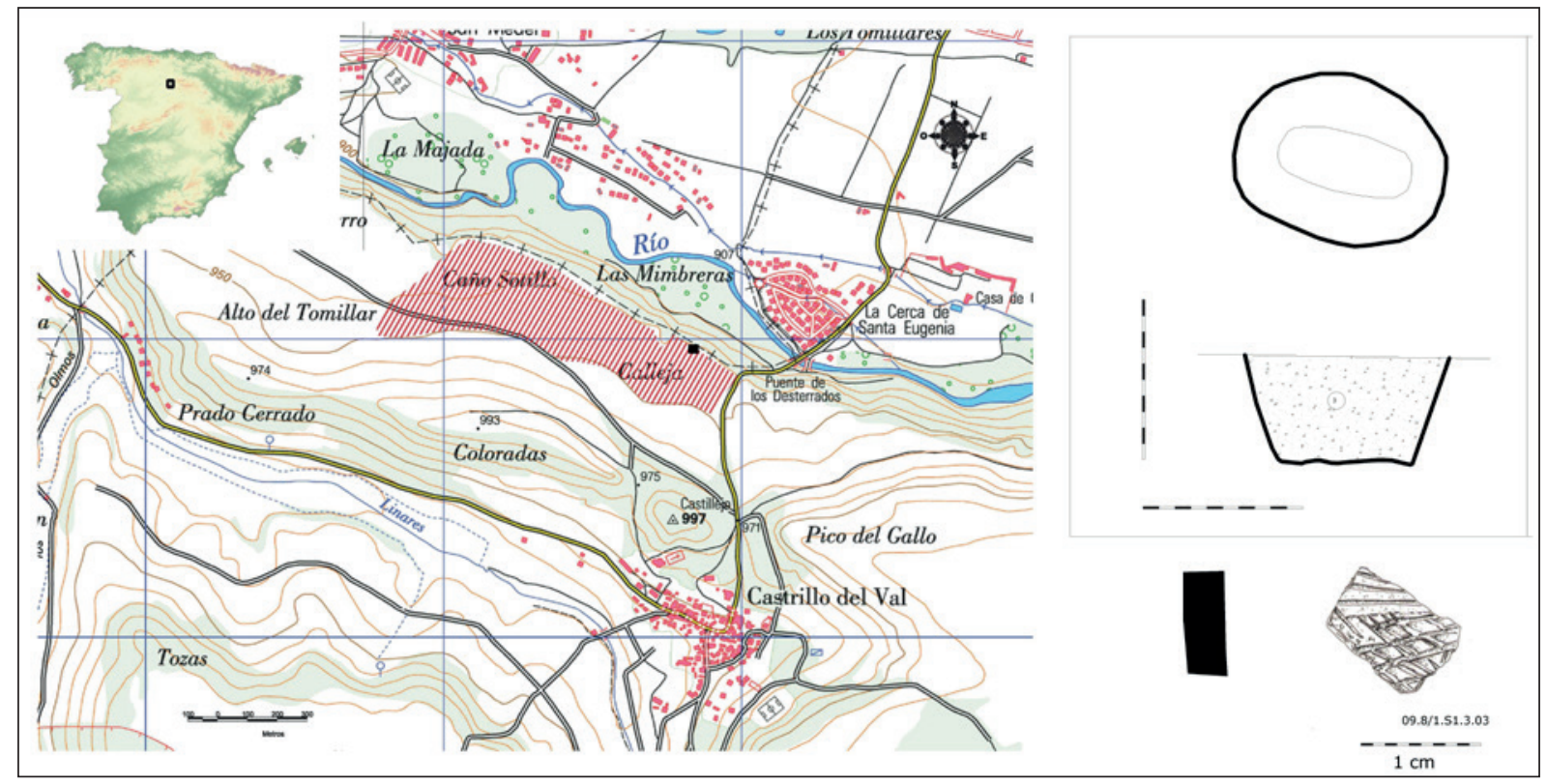

Figura 8. Ubicación de La Mata. El cuadrado representa la localización del sondeo. A la derecha se incorpora la planta y sección del hoyo (Alonso 2009) y el fragmento campaniforme documentado en su interior.

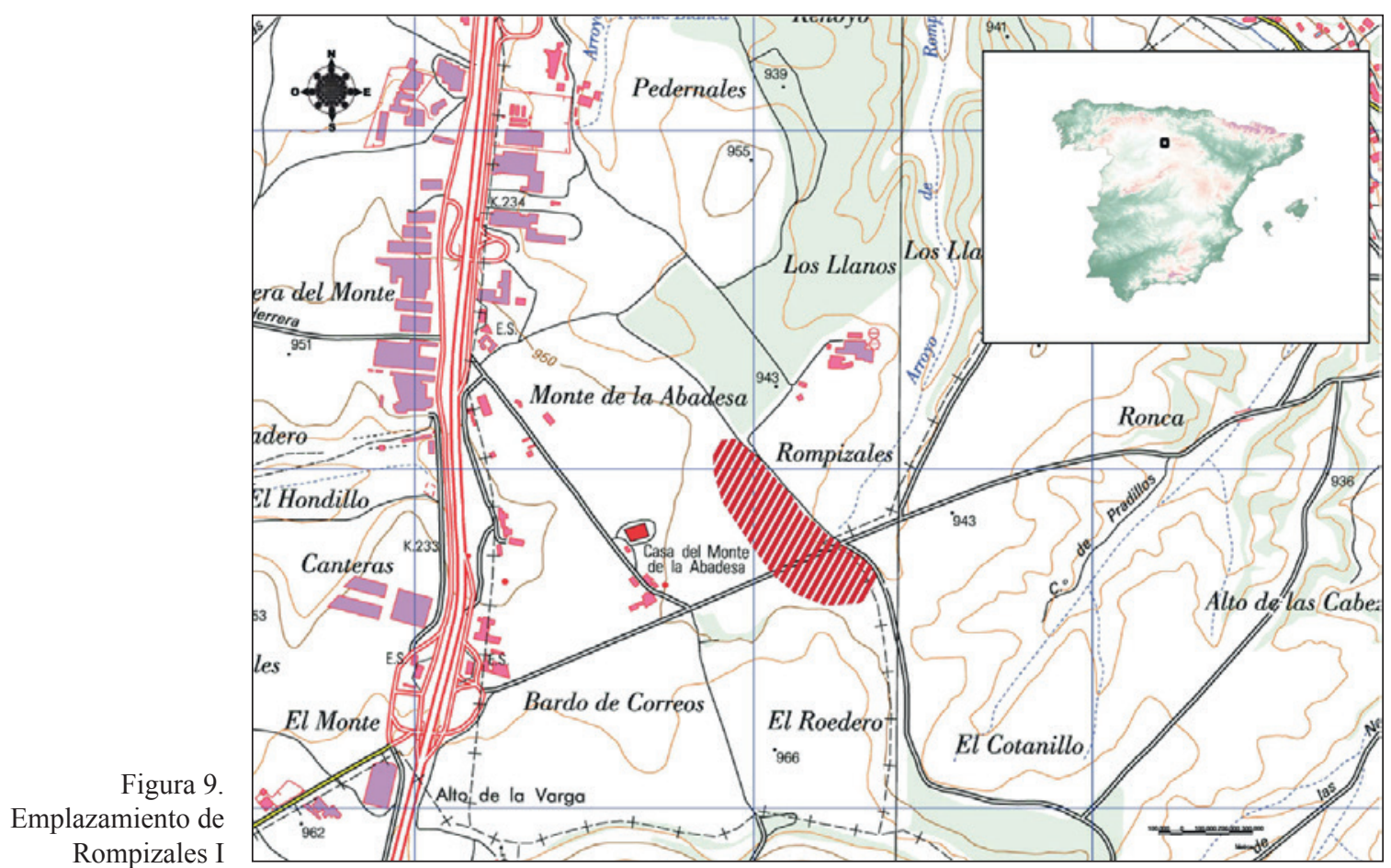




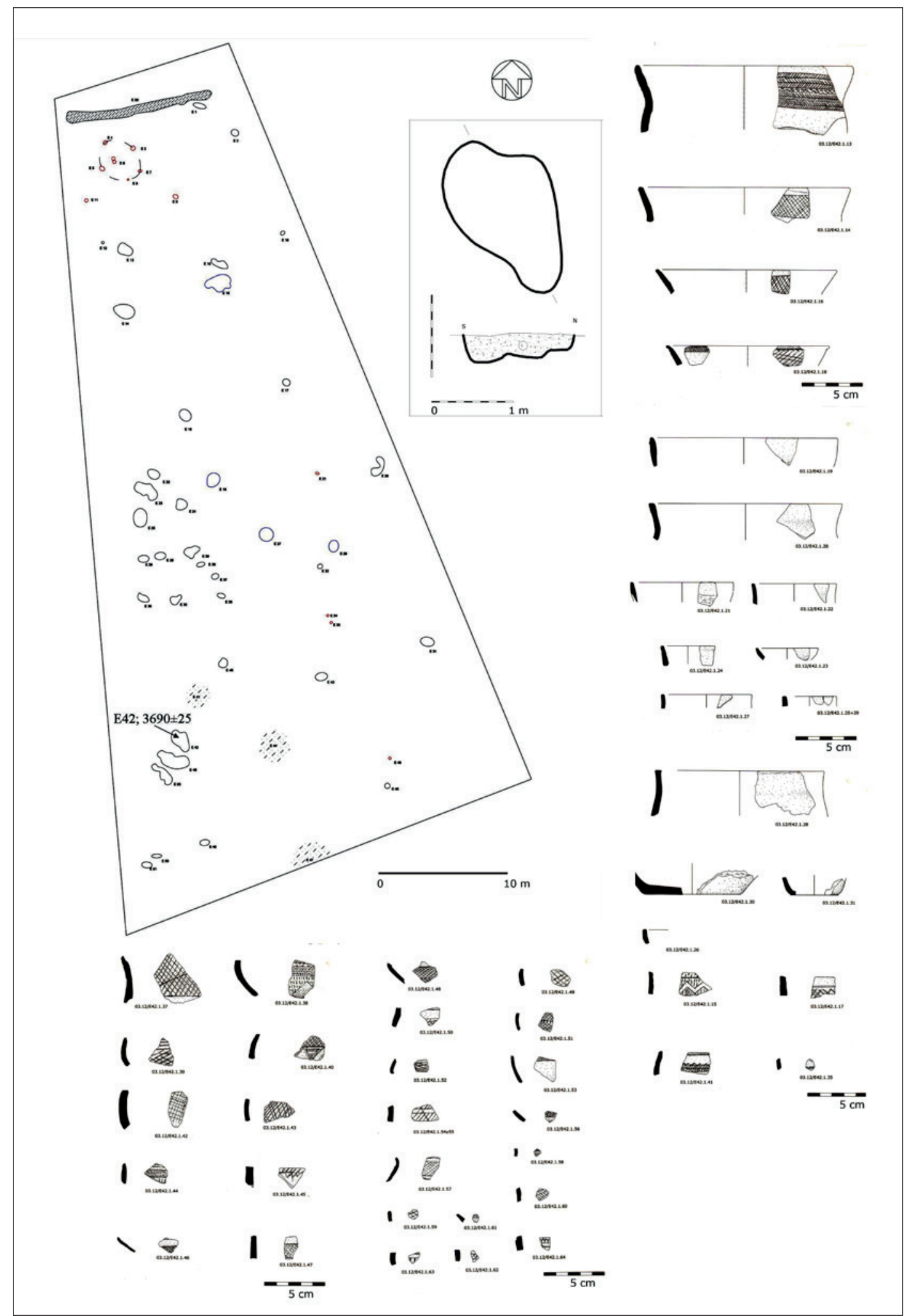

Figura 10. Planta general de Rompizales I (Alonso 2003), donde se indica el contexto de procedencia de la muestra datada. La figura incorpora planta y sección de la fosa junto a los elementos cerámicos significativos. 


\subsubsection{Túmulo IL.C1 de Cótar}

El proyecto contaba con pocos contextos campaniformes y, mucho menos, de tipo funerario. Por esta razón, se decidió completar las dataciones con una procedente del Túmulo de Cótar IL.C1 de Cótar. El monumento funerario se encuentra situado en el borde de una lengua de páramo que domina el curso del Arroyo de Cótar (fig. 11). Este yacimiento, excavado en los años 80 del siglo XX (Uríbarri y Martínez 1987), contaba con restos óseos humanos procedentes del nivel II de la fosa de inhumación detectada bajo el túmulo (fig. 12), acompañados de cerámicas decoradas con motivos del campaniforme Internacional y Ciempozuelos.

La fecha obtenida es prácticamente contemporánea a las obtenidas en La Mata y Rompizales I y pone de manifiesto la simultaneidad de las manifestaciones arqueológicas domésticas y las funerarias. Todas se ciñen al tramo final del periodo de estudio y manifiestan una curiosa problemática a pesar de lo limitado del número de dataciones campaniformes disponibles. Nos referimos, en concreto, al hiato que se manifiesta entre las dataciones del Precampaniforme y las del Campaniforme. Hay que tener en cuenta que el número de contextos campaniformes datados es muy reducido, sobre todo el relacionado con los estilos considerados tradicionalmente más antiguos, como el Internacional o el Puntillado Geométrico. Por lo tanto, las tres determinaciones dan cuenta solo de la fase final del ciclo.

\subsection{Valoración inicial}

Como comentario final a los resultados es necesario recalcar uno de los aspectos fundamentales del trabajo: la determinación de sincronías y diacronías en el registro. En este sentido, observamos varios hitos en los resultados. Un punto de partida, situado en torno al 2900 cal BC, al que sigue un periodo de vigencia de los hábitats de varias centurias que viene a terminar en torno al 2450 cal BC. Durante este momento conviven los yacimientos de El Púlpito, Fuente Celada y El Hornazo.

Tras esta primera fase, se reconocen dos determinaciones a caballo entre la fase inicial (Precampaniforme) y la fase final (Campaniforme), en una transición no muy clara que implica la desaparición del repertorio material precampaniforme y su sustitución por el campaniforme del estilo Ciempozuelos. En esta segunda fase sólo parecen seguir vigentes los hábitats de El Púlpito y Fuente Celada.

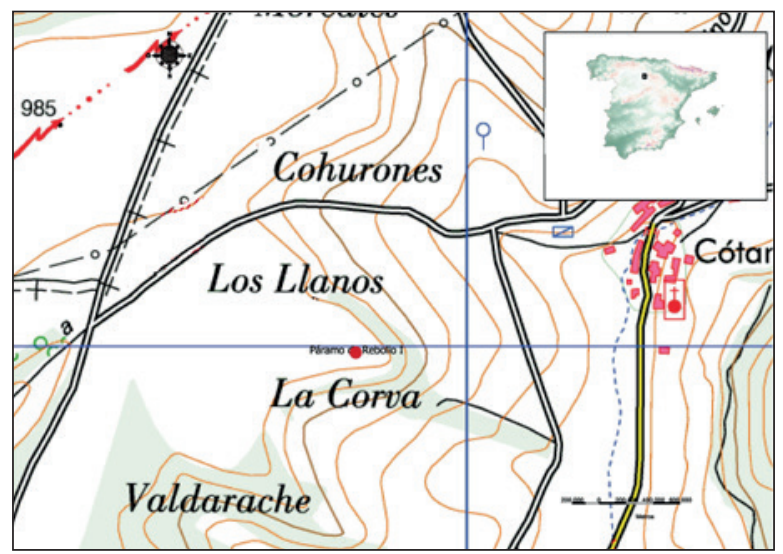

Figura 11. Localización del Túmulo IL.C1 de Cótar.

Un aspecto interesante del registro viene determinado por la sincronía del fenómeno funerario integrado en los hábitats del Precampaniforme y su situación de modernidad respecto a los mismos. La situación expresada a través de tales manifestaciones puede remitir al ámbito de las relaciones sociales y a la potencial conflictividad intragrupal de las comunidades calcolíticas, precisamente en un momento en el que se detecta el fin de algunos de estos hábitats y que supone una reordenación del hábitat.

Clausurados los hábitats anteriores, se ocupan nuevos emplazamientos, de los que son ejemplos los yacimientos de La Mata y Rompizales I. Esta situación se acompaña de la construcción de monumentos funerarios de nueva planta como el Túmulo IL.C1 de Cótar. El final del ciclo calcolítico, a la luz de los resultados, se sitúa en el 1900 cal BC., lo cual concuerda con lo conocido para el conjunto de la Meseta Norte (Garrido 2000: 195-98; Garrido et al 2005: 445-46).

\section{DISCUSIÓN: EL MARCO CRONOLÓGICO DEL CALCOLÍTICO EN LA CMA}

Las dataciones obtenidas han posibilitado el establecimiento de un trasfondo temporal operativo para establecer las relaciones tanto diacrónicas como sincrónicas de las diferentes entidades arqueológicas. Gracias a este análisis se ha completado la información proporcionada por los yacimientos kársticos de la Sierra de Atapuerca. En este sentido, las fechas obtenidas en contextos al aire libre permiten disponer de una visión más completa del registro arqueológico, ampliando la información ofrecida por unos contextos tan particulares como son las cuevas, en un marco geográfico donde suponen una excepción. 


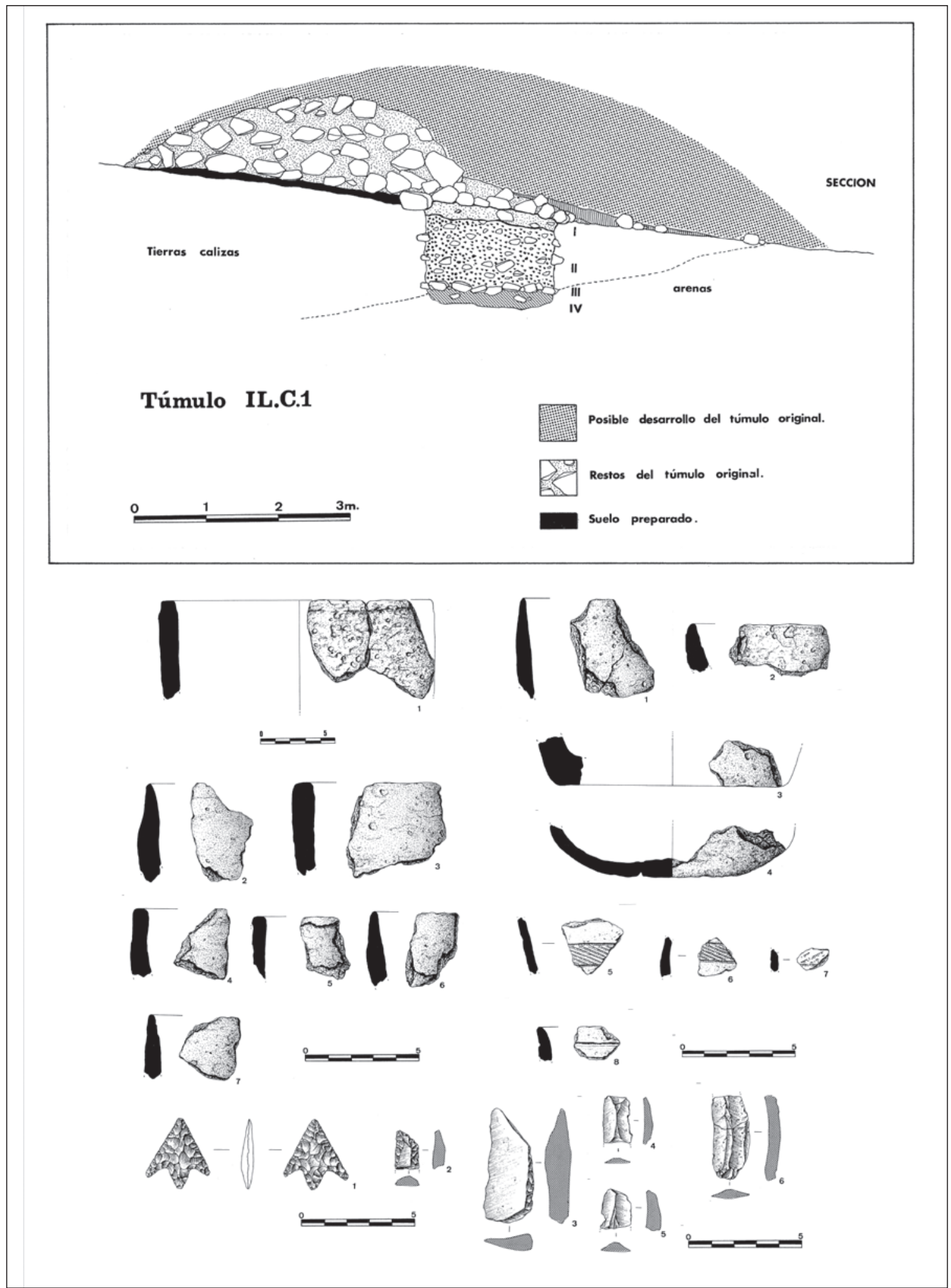

Figura 12. Sección del Túmulo de Cótar y material arqueológico procedente de la excavación. Fuente Uríbarri Angulo y Martínez González 1987. 
Tabla 2. Dataciones radiocarbónicas obtenidas en los yacimientos en cueva de la Cuenca Media del Arlanzón.

\begin{tabular}{|c|c|c|c|c|c|c|c|c|}
\hline Yacimiento & ID & $\begin{array}{l}\text { Fecha } \\
\text { B.P. }\end{array}$ & Calibración $2 \sigma$ & Material & Análisis & Adscripción & Contexto & Bibliografía \\
\hline El Mirador & $\begin{array}{c}\text { Beta- } \\
153367\end{array}$ & 4780,40 & $\begin{array}{r}3648(88.2 \%) 3512 \\
3425(7.2 \%) 3382\end{array}$ & Carbón & AMS & Neolítico & MIR-6 & $\begin{array}{l}\text { Vergés et al } \\
\quad 2008\end{array}$ \\
\hline $\begin{array}{l}\text { El Portalón } \\
\text { de Cueva } \\
\text { Mayor }\end{array}$ & $\begin{array}{c}\text { Beta- } \\
197389\end{array}$ & 4440,50 & $\begin{array}{r}3336(32.6 \%) 3210 \\
3193(8.1 \%) 3151 \\
3139(54.6 \%) 2924\end{array}$ & Diente & AMS & Calcolítico & Nivel 7/8 & $\begin{array}{l}\text { Carretero } \\
\text { et al } 2008\end{array}$ \\
\hline $\begin{array}{l}\text { El Portalón } \\
\text { de Cueva } \\
\text { Mayor }\end{array}$ & $\begin{array}{l}\text { Beta- } \\
153363\end{array}$ & 3910,70 & $\begin{array}{r}2576(95.1 \%) 2200 \\
2159(0.3 \%) 2154\end{array}$ & $\begin{array}{l}\text { Sedimento } \\
\text { orgánico }\end{array}$ & estándar & $\begin{array}{c}\text { Transición } \\
\text { Calcolítico- } \\
\text { Bronce Antiguo }\end{array}$ & Nivel 6 & $\begin{array}{l}\text { Carretero } \\
\text { et al } 2008\end{array}$ \\
\hline $\begin{array}{l}\text { El Portalón } \\
\text { de Cueva } \\
\text { Mayor }\end{array}$ & $\begin{array}{c}\text { Beta- } \\
184843\end{array}$ & 3700,70 & $2292(95.4 \%) 1899$ & Carbón & estándar & Bronce Antiguo & Nivel 5 & $\begin{array}{l}\text { Carretero } \\
\text { et al } 2008\end{array}$ \\
\hline $\begin{array}{l}\text { El Portalón } \\
\text { de Cueva } \\
\text { Mayor }\end{array}$ & $\begin{array}{c}\text { Beta- } \\
184839\end{array}$ & 3740,40 & $\begin{array}{r}2285(7.8 \%) 2247 \\
2234(87.6 \%) 2030\end{array}$ & Carbón & AMS & Bronce Antiguo & Nivel 5 & $\begin{array}{l}\text { Carretero } \\
\text { et al } 2008\end{array}$ \\
\hline $\begin{array}{l}\text { El Portalón } \\
\text { de Cueva } \\
\text { Mayor }\end{array}$ & $\begin{array}{l}\text { Beta- } \\
224079\end{array}$ & 3670,40 & $\begin{array}{r}2195(3.2 \%) 2172 \\
2145(92.2 \%) 1939\end{array}$ & Diente & AMS & Bronce Antiguo & Nivel 5 & $\begin{array}{l}\text { Carretero } \\
\text { et al } 2008\end{array}$ \\
\hline El Mirador & $\begin{array}{l}\text { Beta- } \\
153366\end{array}$ & 3670,40 & $\begin{array}{r}2285(7.8 \%) 2247 \\
2234(87.6 \%) 2030\end{array}$ & $\begin{array}{l}\text { Hueso } \\
\text { humano }\end{array}$ & AMS & Bronce Antiguo & Nivel 4A & $\begin{array}{l}\text { Cáceres } \\
\text { et al } 2007\end{array}$ \\
\hline El Mirador & $\begin{array}{l}\text { Beta- } \\
182041\end{array}$ & 3900,40 & $\begin{array}{r}2481(92.5 \%) 2280 \\
2250(2.1 \%) 2230 \\
2220(0.7 \%) 2211\end{array}$ & $\begin{array}{l}\text { Hueso } \\
\text { humano }\end{array}$ & AMS & Bronce Antiguo & Nivel 4A & $\begin{array}{l}\text { Cáceres } \\
\text { et al } 2007\end{array}$ \\
\hline El Mirador & $\begin{array}{l}\text { Beta- } \\
182042\end{array}$ & 3830,40 & $\begin{array}{r}2460(91.4 \%) 2196 \\
2170(4.0 \%) 2147\end{array}$ & $\begin{array}{l}\text { Hueso } \\
\text { humano }\end{array}$ & AMS & Bronce Antiguo & Nivel 4A & $\begin{array}{l}\text { Cáceres } \\
\text { et al } 2007\end{array}$ \\
\hline
\end{tabular}

Antes de comentar el conjunto de los datos, es necesario hacer alguna puntualización observando los procedentes de las cavidades de la Sierra de Atapuerca (tab. 2). Entre ellos sólo existen dos adscripciones nominalmente calcolíticas. Los investigadores sitúan el resto dentro de otras fases: en el Neolítico y, mayoritariamente, en el Bronce Antiguo (Cáceres et al. 2007; Carretero et al. 2008; Ortega et al. 2008; Vergés et al. 2002; Vergés et al. 2008). Desde nuestro punto de vista, tales atribuciones no visibilizan el rico registro calcolítico de las cavidades - piezas con pastillas repujadas, líneas simples incisas y triángulos rellenos de puntos, así como campaniformes de estilo internacional o Ciempozuelos (Apellániz y Domingo 1987; Juez 2005; Mínguez 2005: 284)- que acompaña a los enterramientos que se han documentado en ambas cuevas y que parecen constituir panteones de uso secular. Este uso aparentemente intenso y prolongado no se corresponde con la baja representación del Calcolítico en la denominación de estas fechas, mientras que el Bronce Antiguo, aunque se acompañe de materiales de esta atribución, aparece sobredimensionado.

Dentro del conjunto se ha incluido a pesar de su antigüedad la fecha del nivel 6 de la cueva de El Mirador, debido a que aparece relacionada con pastillas repujadas (Vergés et al. 2008) y tampoco desentona con otras que permiten establecer la aparición de estos materiales propios del Calcolítico meseteño en torno al 3600 cal BC (Estremera 2003). Es cierto que, al proceder de carbón, la datación puede proporcionar una antigüedad excesiva para el depósito debido a los efectos del fenómeno de la "madera antigua". En ese sentido, las dataciones más antiguas que se reconocen en otros lugares de la Meseta proponen como fecha inicial del Calcolítico el 3300 cal. BC (Cantalapiedra e Ismodes 2010; Fabián 2006; Santonja et al. 1982). En todo caso, los 
datos manifiestan un periodo indefinido que se puede entender como una fase inicial del Calcolítico, un periodo formativo, que se desarrolla durante el periodo comprendido entre el 3600/3300-3000 cal BC con pocas dataciones atestiguadas. Los rasgos de los contextos de este tramo reúnen un buen conjunto de características que somos capaces de reconocer en el III milenio cal B.C. La duda sobre su verdadera integración en el Calcolítico se basa sobre todo en el desconocimiento del registro arqueológico del IV milenio cal $\mathrm{BC}$, que impide valorar si supone realmente una fase formativa de las formaciones propias del Calcolítico o la última manifestación del Neolítico en este sector. Nuestra opinión es considerarla como una fase formativa debido a que, desde el punto de vista material, encontramos más similitudes con las manifestaciones arqueológicas del III milenio cal B.C. que con sus precedentes. Ahora bien, dados los escasos datos disponibles para dilucidar esta cuestión se impone como una orientación preferente de los futuros trabajos que emprendamos.

En el extremo contrario se ubican aquellas referidas al Bronce Antiguo (tab. 2). En todo caso, creemos que la atribución debe hacer mención al periodo de transición Calcolítico Final/Bronce Antiguo, donde se solapan fechas y alternan materiales campaniformes (Ciempozuelos) (Castro et al. 1996: 146; Garrido 2000: 195-98), con otros de atribución al Bronce Antiguo-Pleno (Horizonte Parpantique). Este periodo de transición lo podemos establecer entre 2200-1900 cal BC (Rodríguez 2007: 274; 2012: 152; Samaniego et al. 2002: 96). Este es un fenómeno general cuya causa aún permanece inexplicada. No obstante, es preciso señalar que el fenómeno no supone un cambio sustancial a escala global, que, en este sector de la Meseta, es perceptible básicamente en la sustitución de unos tipos cerámicos por otros. En términos históricos, tanto Calcolítico como Edad del Bronce no se pueden deslindar en la Meseta, se integran dentro de un mismo ciclo histórico: la Primera Edad de los Metales (Bernabeu 2003: 120; Díaz del Río 2001: 16; Vicent 1995: 177). Bien es cierto, que este fenómeno arqueológico debería ser sometido a un programa de datación específico que resuelva el problema de asociación de fechas absolutas a materiales arqueológicos con el fin de poder ser explicado. No obstante, más allá de esta ordenación, el solapamiento e interacción entre ambos grupos arqueológicos, desde nuestro punto de vista, se puede relacionar con las dinámicas condiciones de reproducción social de las comunidades campesinas de tipo segmentario, pero el debate excede el marco de este trabajo.
Otro aspecto llamativo a escala local es la alternancia entre las dataciones de los contextos al aire libre y las obtenidas en las cavidades de la Sierra de Atapuerca durante el Precampaniforme. Las más antiguas están documentadas en las cavidades de El Portalón de Cueva Mayor y El Mirador, dentro del lapso 3600-2920 cal BC. En estos ambientes les sigue un hiato de algo más de cuatro centurias que, precisamente, es el más representado en las determinaciones obtenidas al aire libre. En El Mirador este lapso está relacionado en la cavidad por un único estrato (MIR-5) con evidencias incompatibles con la presencia humana (egagrópilas) (Vergés et al. 2008). En El Portalón de Cueva Mayor el registro no es muy esclarecedor aún y, aunque las fechas muestran este vacío (Carretero et al. 2008), entre los materiales recuperados en el pozo que afecta a buena parte de la estratigrafía (Juez 2005) existen objetos de clara de atribución precampaniforme. Para el hiato inmediatamente posterior, las cavidades proporcionan un buen número de determinaciones que se corresponden con las manifestaciones arqueológicas campaniformes en el espacio regional. En el caso de las cuevas, las pruebas parecen apuntar a la utilización funeraria durante este ciclo, lo que proporciona una evidencia complementaria a los hábitats que se reconocen al aire libre.

Las determinaciones procedentes de cuevas y las obtenidas en contextos al aire libre se pueden combinar junto a los datos arqueológicos procedentes de los contextos de referencia con el fin de establecer una periodización para las entidades arqueológicas del Calcolítico en la CMA. Si observamos todos los datos se pueden distinguir, al menos, cuatro momentos diferenciados dentro del Calcolítico local. Hemos de hacer hincapié en que no son fases históricas, sino una secuencia que hace referencia a aspectos tipológicos que pueden ser empleados en la determinación de fechas relativas en ausencia de dataciones:

1. 3600-2900 cal BC. Aparición de rasgos morfológicos propios del repertorio calcolítico, como las pastillas repujadas y los bordes con moldura. Las dataciones informan de pocos lugares con este repertorio cerámico.

2. 2900-2450 cal BC. La vajilla cerámica amplía la variedad ornamental incorporando, junto a las pastillas repujadas y los bordes con moldura, perforaciones, líneas horizontales incisas, acanaladuras bajo el borde, triángulos rellenos de puntos y algunas piezas, muy pocas, con líneas pintadas. Hay una mayor frecuencia de dataciones en este rango temporal, que se suele asimilar a la existencia de un mayor número de yacimientos. 
3. 2450-2200 cal BC. En este periodo se constata la pervivencia los elementos decorativos anteriores en los ambientes domésticos. A tenor de lo que ocurre en otros ámbitos meseteños, parece que se comienza a utilizar la vajilla campaniforme en los contextos funerarios, sobre todo los estilos internacionales. Este hecho todavía deber ser comprobado en el ámbito local. La introducción del Campaniforme es algo más tardía que en el sur de la Meseta, donde se puede retrotraer la fecha hasta el $2650 \mathrm{cal}$ BC. La única excepción es la fecha de la Cueva de los Enebralejos, que es tremendamente antigua y que hay que tomar con cautela.

4. 2200-1900 cal BC. En los espacios domésticos la vajilla común conserva rasgos precampaniformes aunque el repertorio formal es más reducido, mientras que la vajilla ornamentada se adecua a los rasgos morfológicos y decorativos Campaniformes, en este caso vinculados al estilo Ciempozuelos, aunque con ciertos rasgos particulares del oriente de la Meseta Norte (Carmona 2010; Garrido 2000). Además, en ciertos contextos se reconocen algunos rasgos que se asocian a la cerámica del Bronce Antiguo, vinculadas al "horizonte Parpantique" (22001750 cal BC), como la aparición de las primeras carenas elevadas y los cordones.

Todos estos datos permiten ordenar con algo más de precisión los elementos formales empleados en la datación relativa. En primer lugar, el periodo definido por la mayoría de los investigadores como Calcolítico Precampaniforme se comprende dentro de la cronología 3600 y 2200 cal. BC (Castro et al. 1996: 100-02; Estremera 2003: 185-86; Fabián 2006: 446-47). Se caracteriza, al oriente de la Meseta Norte, por la presencia de cerámica de paredes lisas y formas simples, decoradas con pastillas repujadas, acanaladuras simples y líneas incisas bajo el borde, triángulos rellenos de puntos y el registro de puntas pedunculadas de retoque plano. En la CMA faltan otras manifestaciones como la cerámica peinada, la simbólica y los morillos o crecientes, tan característicos del occidente meseteño. De manera residual aparecen otras manifestaciones como la cerámica pintada. En torno a $2450 \mathrm{cal} \mathrm{BC}$ se reconocen cambios en el registro que no se manifiestan ni de manera brusca ni con la misma intensidad en todo el territorio, tal y como demuestra el conjunto de materiales tipológicamente precampaniformes que convive parcialmente con el fenómeno representado por los elementos campaniformes en el marco de la Meseta al menos durante 200 años. No obstante, para el caso del
Arlanzón no se ha confirmado tal convivencia. Quizá esta particularidad se deba al bajo número de muestras campaniformes, sobre todo en relación a determinados contextos, como los que documentan Campaniforme Internacional, considerado tradicionalmente el más antiguo. La única muestra del ámbito del Arlanzón procede de un ámbito funerario y remite a cronologías similares a la de los hábitats con Ciempozuelos. Al final del ciclo Calcolítico (2100-1900 cal BC), la cerámica ornamentada de tipo campaniforme sustituye a la precampaniforme en todos los ámbitos, tanto los funerarios como los domésticos.

A modo de conclusión podemos indicar que el trabajo realizado solo ha permitido soslayar parcialmente el problema que anunciábamos al inicio. Es necesario insistir en programas de este tipo para poder afrontar todos los cabos sueltos que se observan. No se ha de olvidar que, además, la ordenación temporal de los datos arqueológicos no es un fin en sí mismo, sino que ha de tener su recorrido como medio para explicar los procesos (pre)históricos. Este estudio cubre, al menos parcialmente, esta faceta para un ámbito geográfico apenas estudiado hasta el momento, donde la interpretación de los fenómenos integrados en el Calcolítico con los datos cronológicos precedentes resultaba verdaderamente difícil.

\section{Agradecimientos}

Quiero expresar mi agradecimiento a la Fundación Gutiérrez-Manrique, que financió el trabajo a través del proyecto Dataciones absolutas de contextos calcolíticos de la Cuenca Media del Arlanzón (Burgos), $\mathrm{y}$ al Programa de ayudas para la contratación de personal de reciente titulación universitaria, cofinanciado por la Junta de Castilla y León y el Fondo Social Europeo, sin cuyo apoyo económico este trabajo no hubiera sido posible.

\section{BIBLIOGRAFÍA}

Alameda Cuenca-Romero, M.C.; Carmona Ballestero, E.; Pascual Blanco, S.; Martínez Díez, G. y Diez Pastor, C. (2011): "El "Campo de Hoyos" calcolítico de Fuente Celada (Burgos): datos preliminares y perspectivas". Complutum 22(1): 47-69. doi: 10.5209/rev_CMPL.2011.v22.n1.3.

Alonso Fernández, C. (2003): Excavación arqueológica en el yacimiento Rompizales I (Burgos). 
Servicio Territorial de Cultura de Burgos, Junta de Castilla y León (Informe técnico inédito).

Alonso Fernández, C. (2009): Excavación arqueológica en los yacimientos "La Mata" y "Camino de Quintanilla", en Castrillo del Val, "Llanos de Villalval" en Rubena, y "Fuente Entún/Castrillas" y "Capillejas" en Cótar (Burgos). Trabajos integrados en el proyecto de construcción LAT 220 k.v. Set Carcedo-Set Villimar. Servicio Territorial de Cultura de Burgos, Junta de Castilla y León (Informe técnico inédito).

Anderson-Whymark, H. y Thomas, J. (2012): Regional Perspectives on Neolithic Pit Deposition: Beyond the Mundane, Neolithic Studies Group Seminar Papers 12. Oxford, Oxbow Books.

Apellániz, J.M. y Domingo Mena, D. (1987): Estudios sobre Atapuerca (Burgos): II. Los materiales de superficie del Santuario de la Galería del Sílex. Bilbao, Universidad de Deusto.

Bellido Blanco, A. (1996): "Los campos de hoyos. Inicio de la economía agrícola en la Submeseta Norte". Studia Archaeologica 85: 69-97.

Benet, N.; Pérez, R. y Santonja, M. (1996): "Evidencias campaniformes en el valle medio del Tormes", en II Congreso de Arqueología Peninsular: 449-70. Zamora, Fundación Rei Afonso Henriques.

Bernabeu, J. (2003): "Del Neolítico a la Edad del Bronce", en G. Vega Toscano, J. Bernabeu Aubán y T. Chapa Brunet (eds.), La Prehistoria, Historia de España 1: 113-74. Madrid, Síntesis.

Blanco González, A. (2011): "Práctica social, memoria y ritual en Cogotas I. Esbozo teórico para un enfoque renovado". Trabajos de Prehistoria 68(1): 12346. doi: 10.3989/tp.2011.11062.

Cáceres, I.; Lozano, M. y Saladié, P. (2007): “Evidence for Bronze Age Cannibalism in El Mirador Cave (Sierra de Atapuerca, Burgos, Spain)". American Journal of Physical Anthropology 133(3): 899-917. doi: $10.1086 / 653807$

Cantalapiedra Jiménez, V. e Ismodes Ezcurra, A. (2010): "Datación del yacimiento por C14 AMS: una cronología absoluta", en V. Cantalapiedra Jiménez, V. y A. Ismodes Ezcurra (eds.), El yacimiento arqueologico de Aguas Vivas. Prehistoria Reciente en el valle del río Henares (Guadalajara): 45-52. Madrid, La Ergástula.

Carmona Ballestero, E. (2010): Prestigio y emulación en espacios marginales: la cerámica campaniforme de Paulejas (Quintanilla del Agua, Burgos). Burgos, Universidad de Burgos.

Carmona Ballestero, E. (2012): Las comunidades campesinas calcolíticas del Valle Medio del Arlanzón
(3000-1900 cal BC.): procesos históricos y transformaciones, Universidad de Burgos. Tesis Doctoral inédita.

Carretero, J.M.; Ortega, A.I.; Juez, L.; Pérez-González, A.L.; Arsuaga, J.; Pérez Martínez, R. y Ortega, M. C. (2008): “A Late Pleistocene-Early Holocene archaeological sequence of Portalón de Cueva Mayor (Sierra de Atapuerca, Burgos, Spain)". Munibe 59: 67-80.

Castro, P.; Lull, V. y Micó, R. (1996): Cronología de la Prehistoria Reciente de la Península Ibérica y Baleares (c. 2800-900 cal ANE). BAR International Series 652. Oxford, Archaeopress.

Cunliffe, B. (1992): "Pits, preconceptions and propitiation in British Iron Age". Oxford Journal of Archaeology 11(1): 69-83. http://dx.doi. org/10.1111/j.1468-0092.1992.tb00257.x

Chapman, J. (2000): "Pit-digging and Structured Deposition in the Neolithic and Copper Age". Proceedings of Prehistoric Society 66: 61-87.

Delgado Arceo, M. E. y Villanueva Martín, L. (2010): Informe Técnico de las excavaciones en el yacimiento arqueológico "El Púlpito”. Proyecto constructivo "Circunvalación de Burgos Bu-30. Tramo: Villalbilla de Burgos-Quintanadueñas" (Provincia de Burgos). Servicio de Territorial de Cultura de Burgos, Junta de Castilla y León (Informe técnico inédito).

Delibes de Castro, G. y Herrán Martínez, J. I. (2007): La Prehistoria, Biblioteca Básica de Valladolid. Valladolid, Diputación de Valladolid.

Delibes de Castro, G.; Benet Jordana, N.; Pérez Martín, R. y Zapatero Magdaleno, M. (1997): "De la tumba dolménica como referente territorial, al poblado estable: notas sobre el hábitat y las formas de vida de las comunidades megalíticas de la Submeseta Norte", en A.A. Rodríguez (ed.), O Neolítico Atlántico e as orixes do megalitismo: 779-808. Santiago de Compostela, Universidade de Santiago de Compostela.

Delibes de Castro, G.; Fabián García, F.J.; Fernández Manzano, J.; Herrán Martínez, J. I.; Santiago Pardo, J. y Val Recio, J. del (1996): "Los más antiguos testimonios del uso y producción de metal en el suroeste de la submeseta norte: consideraciones tipológicas, tecnológicas y contextuales”, en A. Rodríguez (ed.), Humanitas: estudios en homenaje al Prof. Dr. Carlos Alonso del Real: 163-201. Santiago de Compostela, Universidad de Santiago de Compostela.

Díaz del Río, P. (2001): La formación del paisaje agrario: Madrid en el III y II milenios BC, Arqueología, Paleontología y Etnografía. Madrid, Consejería de las Artes de la Comunidad de Madrid. 
Díaz del Río, P. (2003): "Recintos de fosos del III milenio a.C. en la Meseta Peninsular". Trabajos de Prehistoria 60(2): 61-78.

Estremera Portela, M. S. (2003): Primeros agricultores y ganaderos en la Meseta Norte: el Neolítico de la Cueva de La Vaquera (Torreiglesias, Segovia), Arqueología en Castilla y León 11. Zamora, Junta de Castilla y León.

Fabián García, F.J. (1995): El aspecto funerario durante el calcolitico y los inicios de la Edad del Bronce en la Meseta Norte. Salamanca, Universidad de Salamanca.

Fabián García, F.J. (2006): El IV y III milenio a.C. en el Valle del Amblés (Ávila), Arqueología en Castilla y León. Monografías 5. Valladolid, Junta de Castilla y León.

Fabián García, F. J. y Blanco González, A. (2012): "Cuatro enterramientos en hoyo del Cerro de la Cabeza (Ávila)". Complutum 23(1): 99-120. http://dx.doi.org/10.5209/rev_CMPL.2012.v23. n1.39533

Garrido Pena, R. (2000): El Campaniforme en la Meseta Central de la Península Ibérica (c. 2500-2000 a.C.). BAR International Series 892. Oxford, Archaeopress.

Garrido Pena, R.; Rojo Guerra, M. y García-Martínez de Lagrán, I. (2005): "El Campaniforme en la Meseta Central de la Península Ibérica”, en M.A. Rojo Guerra, R. Garrido Pena e I. García-Martínez de Lagrán, El Campaniforme en la Península Ibérica y su contexto europeo: 411-37. Valladolid, Universidad de Valladolid.

González-Gómez, C. (1991): "University of Granada Radiocarbon Dates V". Radiocarbon 33(3): 367-73.

González-Gómez, C. (1992): "University of Granada Radiocarbon Dates VI". Radiocarbon 34(1): 133-39.

Herrán Martínez, J. I. (1986): El yacimiento calcolítico de Los Cercados en Mucientes. Sobre los comienzos de la metalurgia en el Valle Medio del Duero. Universidad de Valladolid. Memoria de Licenciatura, inédita.

Jiménez Jáimez, V. y Márquez Romero, J. E. (2006): "Aquí no hay quien viva". Sobre las casas-pozo en la Prehistoria de Andalucía durante el IV y III milenios AC". Spal 15: 39-49. http://dx.doi. org/10.12795/spal.2006.i15.03

Jimeno Martínez, A.; Fernández, J. J. y Revilla, M. L. (1988): “Asentamientos de la Edad del bronce en la provincia de Soria: consideraciones sobre los contextos culturales del Bronce Antiguo". Noticiario Arqueológico Hispánico 30: 85-118.
Juez Aparicio, L. (2005): Estudio tipológico y contextualización de los materiales cerámicos recuperados en la Campaña de 2000 en el yacimiento del Portalón de Cueva Mayor (Sierra de Atapuerca, Burgos). Universidad de Burgos, Suficiencia Investigadora, inédita.

Liseau, C.; Blasco, C.; Ríos, P.; Vega, J.; Menduiña, R.; Blanco, J.F.; Baena, J.; Herrera, T.; Petri, A. y Gómez, J. L. (2008): "Un espacio compartido por vivos y muertos: El poblado calcolítico de fosos de Camino de las Yeseras (San Fernando de Henares, Madrid)". Complutum 19(1): 97-120.

Márquez Romero, J. E. y Jiménez Jáimez, V. (2010): Recintos de fosos. Genealogía y significado de una tradición en la Prehistoria del suroeste de la Península Ibérica (IV-III milenios AC). Málaga, Universidad de Málaga.

Martín Valls, R. y Delibes de Castro, G. (1989): La Cultura del Vaso Campaniforme en las campiñas meridionales del Duero: el enterramiento de Fuente-Olmedo. Valladolid, Diputación de Valladolid.

Martínez Puente, M. E. (1989): El yacimiento Neolítico y de la Edad del Bronce de Los Cascajos-El Blanquillo, Quintanadueñas, Burgos. Universidad de Valladolid. Memoria de Licenciatura, inédita.

Mínguez Álvaro, M. T. (2005): Estudios sobre Atapuerca (Burgos): III. Los materiales del Bronce Final de "El Portalón" de Cueva Mayor. Bilbao, Universidad de Deusto y Excma. Diputación de Burgos.

Moral del Hoyo, S. (2002): La Cueva del Mirador. La Edad del Bronce en la Sierra de Atapuerca 2. Burgos, Ediciones Sierra de Atapuerca.

Municio González, L. y Piñón, F. (1990): “Cueva de los Enebralejos (Prádena, Segovia)”. Numantia III: 51-76.

Ortega, A.I.; Juez, L.; Carretero, J.M.; Ortega, M.C.; Arsuaga, J.L. y Pérez González, A. (2008): “El Neolítico en la nueva secuencia estratigráfica del yacimiento del Portalón de Cueva Mayor (Sierra de Atapuerca, Burgos)", en IV Congreso del Neolítico Peninsular: 221-29. Alicante (2006). Museo Arqueológico de Alicante, Alicante.

Pollard, J. (2001): "The aesthetics of depositional practice". World Archaeology 33 (2): 315-33.

Priego, C. y Quero, S. (1992): "El Ventorro, un poblado prehistórico en los albores de la metalurgia". Estudios de Prehistoria y Arqueología Madrileña 8 (monográfico). Madrid, Ayuntamiento de Madrid.

Reimer, P.J.; Baillie, M.G.L.; Bard, E.; Bayliss, A.; Beck, J.W.; Blackwell, P.G.; Bronk Ramsey, C.; Buck, C.E.; Burr, G.S.; Edwards, R.L.; Friedrich, M.; Grootes, P.M.; Guilderson, T.P.; Hajdas, I.; 
Heaton, T.J.; Hogg, A.G.; Hughen, K.A.; Kaiser, K.F.; Kromer, B.; McCormac, F.G.; Manning, S.W.; Reimer, R.W.; Richards, D.A.; Southon, J.R.; Talamo, S.; Turney, C.S.M.; van der Plicht, J. y Weyhenmeyer, C E. (2009): "IntCal09 and Marine09 radiocarbon age calibration curves, 0-50,000 years cal BP”. Radiocarbon 51 (4): 1111-50.

Richards, C. y Thomas, J. (1984): "Ritual activity and structured deposition in Later Neolithic Wessex", en R. Bradley y J. Gardiner (eds.), Neolithic studies. BAR British Series 133: 189-218. Oxford, Archaeopress.

Rodríguez Marcos, J.A. (2007): Estudio secuencial de la Edad del Bronce en la Ribera del Duero (provincia de Valladolid), Arqueología en Castilla y León. Monografías 7. Valladolid, Junta de Castilla y León.

Rodríguez Marcos, J.A. (2012): “Algunas notas sobre el proceso formativo de la cultura de Cogotas I", en J.A. Rodríguez y J. Fernández (eds.), Cogotas I. Una cultura de la Edad del Bronce en la Península Ibérica. Homenaje a $M^{a}$ Dolores Fernández-Posse: 147-164. Valladolid, Universidad de Valladolid.

Rubinos Pérez, A. (2009): "Límites de la geocronología en el estudio de yacimientos de época histórica". Munibe (Antropologia-Arqueologia) 60: 331-47.

Samaniego Bordiu, B.; Jimeno Martínez, A.; Fernández Moreno, J.J. y Gómez Barrera, J. A. (2002): Cueva Maja (Cabrejas del Pinar, Soria): Espacio y simbolismo en los inicios de la Edad del Bronce, Arqueología en Castilla y León 10. Valladolid, Junta de Castilla y León.

Santonja Gómez, M.; Santonja Alonso, M. y Alcalde, G. (1982): “Aspectos de la ocupación humana en el
Cañón de la Horadada (Palencia)". Publicaciones de la Institución Tello Téllez de Meneses 47: 337-92.

Uríbarri Angulo, J.L. y Martínez González, J.M. (1987): "Primeros asentamientos humanos en el término municipal de la ciudad de Burgos". Caesaraugusta 64: 135-56.

Uríbarri Angulo, J.L., Martínez González, J.M. y Leis Muñoz, I. (1987): Primeros asentamientos humanos en la ciudad de Burgos. Burgos, Aldecoa.

Val Recio, J. del (1992): "El yacimiento calcolítico precampaniforme de Las Pozas en Casaseca de las Chanas (Zamora)". Boletín del Seminario de Estudios de Arte y Arqueología LVIII: 47-62.

Vergés, J.M.; Allué, E.; Angelucci, D.E.; Cebriá, A.; Fontanals, M.; Mányanos, A.; Montero, S.; Moral, S.; Vaquero, M. y Zaragoza, J. (2002): "La Sierra de Atapuerca durante el Holoceno: datos preliminares sobre las ocupaciones de la edad del Bronce en la Cueva de el Mirador (Ibeas de Juarros, Burgos)". Trabajos de Prehistoria 59(1): 107-26.

Vergés, J.M.; Allué, E.; Angelucci, D.E.; Burjachs, F.; Carrancho, A.; Cebria, A.; Expósito, I.; Fontanals, M.; Moral, S.; Rodríguez, A. y Vaquero, M. (2008): "Los niveles neolíticos de la cueva de El Mirador (Sierra de Atapuerca, Burgos): nuevos datos sobre la implantación y el desarrollo de la economía agropecuaria en la submeseta norte", en IV Congreso del Neolítico Peninsular: 418-27. Alicante, Museo Arqueológico de Alicante.

Vicent García, J.M. (1995): "Early social complexity in Iberia: some theoretical remarks", en K. T. Lillios (ed.), The origins of Complex Societies in Late Prehistoric Iberia: 177-83. Michigan, Ann Arbor. 